\title{
TOF-SIMS investigation of degradation pathways occurring in a variety of organic photovoltaic devices - the ISOS-3 inter-laboratory collaboration
}

Andreasen, Birgitta; Tanenbaum, David; Hermenau, Martin; Voroshazi, Eszter; Lloyd, Matthew T.; Galagan, Yulia; Zimmernann, Birger; Kudret, Suleyman; Maes, Wouter; Lutsen, Laurence

Total number of authors:

28

Published in:

Physical Chemistry Chemical Physics

Link to article, DOI:

$10.1039 / \mathrm{c} 2 \mathrm{cp} 41787 \mathrm{a}$

Publication date:

2012

Document Version

Publisher's PDF, also known as Version of record

Link back to DTU Orbit

Citation (APA):

Andreasen, B., Tanenbaum, D., Hermenau, M., Voroshazi, E., Lloyd, M. T., Galagan, Y., Zimmernann, B., Kudret, S., Maes, W., Lutsen, L., Vanderzande, D., Würfel, U., Andriessen, R., Rösch, R., Hoppe, H., TeranEscobar, G., Lira-Cantu, M., Rivaton, A., Uzunolu, G. Y., ... Norrman, K. (2012). TOF-SIMS investigation of degradation pathways occurring in a variety of organic photovoltaic devices - the ISOS-3 inter-laboratory collaboration. Physical Chemistry Chemical Physics, 14(33), 11780-11799. https://doi.org/10.1039/c2cp41787a

\section{General rights}

Copyright and moral rights for the publications made accessible in the public portal are retained by the authors and/or other copyright owners and it is a condition of accessing publications that users recognise and abide by the legal requirements associated with these rights.

- Users may download and print one copy of any publication from the public portal for the purpose of private study or research.

- You may not further distribute the material or use it for any profit-making activity or commercial gain

- You may freely distribute the URL identifying the publication in the public portal 


\title{
TOF-SIMS investigation of degradation pathways occurring in a variety of organic photovoltaic devices - the ISOS-3 inter-laboratory collaboration
}

\author{
Birgitta Andreasen, ${ }^{a}$ David M. Tanenbaum, ${ }^{a b}$ Martin Hermenau, ${ }^{c}$ \\ Eszter Voroshazi, ${ }^{d}$ Matthew T. Lloyd, ${ }^{e}$ Yulia Galagan, ${ }^{f}$ Birger Zimmernann, ${ }^{g}$ \\ Suleyman Kudret, ${ }^{h}$ Wouter Maes, ${ }^{h}$ Laurence Lutsen, ${ }^{i}$ Dirk Vanderzande, ${ }^{h}$ \\ Uli Würfel, ${ }^{g}$ Ronn Andriessen,${ }^{f}$ Roland Rösch,${ }^{j}$ Harald Hoppe, ${ }^{j}$ \\ Gerardo Teran-Escobar, ${ }^{k}$ Monica Lira-Cantu, ${ }^{k}$ Agnès Rivaton, ${ }^{l}$ \\ Gülşah Y. Uzunoğlu, ${ }^{m}$ David S. Germack, ${ }^{n}$ Markus Hösel, ${ }^{a}$ Henrik F. Dam, ${ }^{a}$ \\ Mikkel Jørgensen, ${ }^{a}$ Suren A. Gevorgyan, ${ }^{a}$ Morten V. Madsen, ${ }^{a}$ Eva Bundgaard, ${ }^{a}$ \\ Frederik C. Krebs $^{a}$ and Kion Norrman $* a$
}

Received 30th May 2012, Accepted 4th July 2012

DOI: $10.1039 / \mathrm{c} 2 \mathrm{cp} 41787 \mathrm{a}$

The present work is the fourth (and final) contribution to an inter-laboratory collaboration that was planned at the 3rd International Summit on Organic Photovoltaic Stability (ISOS-3). The collaboration involved six laboratories capable of producing seven distinct sets of OPV devices that were degraded under well-defined conditions in accordance with the ISOS-3 protocols. The degradation experiments lasted up to 1830 hours and involved more than 300 cells on more than 100 devices. The devices were analyzed and characterized at different points of their lifetimes by a large number of non-destructive and destructive techniques in order to identify specific degradation mechanisms responsible for the deterioration of the photovoltaic response. Work presented herein involves time-of-flight secondary ion mass spectrometry (TOF-SIMS) in order to study chemical degradation in-plane as well as in-depth in the organic solar cells. Various degradation mechanisms were investigated and correlated with cell performance. For example, photo-oxidation of the active material was quantitatively studied as a function of cell performance. The large variety of cell architectures used (some with and some without encapsulation) enabled valuable comparisons and important conclusions to be drawn on degradation behaviour. This comprehensive investigation of OPV stability has significantly advanced the understanding of degradation behaviour in OPV devices, which is an important step towards large scale application of organic solar cells.

\footnotetext{
${ }^{a}$ Department of Energy Conversion and Storage, Technical University of Denmark, Frederiksborgvej 399, DK-4000, Roskilde, Denmark.

E-mail:kino@dtu.dk

${ }^{b}$ Department of Physics and Astronomy, Pomona College, Claremont, CA 91711, USA

${ }^{c}$ Arbeitsgruppe Organische Solarzellen (OSOL), Institut für Angewandte Photophysik, Technische Universität Dresden, 01062,

Dresden, Germany

dIMEC, Kapeldreef 75, 3000 Leuven, Belgium and Katholieke Universiteit Leuven, ESAT, Kasteelpark Arenberg 10, 3000, Leuven, Belgium

${ }^{e}$ National Renewable Energy Laboratory, Golden, CO 80401, USA

${ }^{f}$ Holst Centre, High Tech Campus 31, 5656 AE Eindhoven, The Netherlands

${ }^{g}$ Fraunhofer Institute for Solar Energy Systems ISE, Heidenhofstrasse 2, D-79110Freiburg, Germany

${ }^{h}$ Hasselt University, Campus, Agoralaan 1, Building D, WET/OBPC, B-3590 Diepenbeek, Belgium

${ }^{i}$ IMEC, IMOMEC Associated Laboratory, Campus University of Hasselt, Wetenscharpspark 1, B-3590, Diepenbeek, Belgium

${ }^{j}$ Institute of Physics, Ilmenau University of Technology, Weimarer Str. 32, 98693, Ilmenau, Germany

${ }^{k}$ Centre d'Investigació en Nanociència i Nanotecnologia (CIN2, CSIC), Laboratory of Nanostructured Materials for Photovoltaic Energy, ETSE, Campus UAB, Edifici Q, 2nd Floor, E-08193, Bellaterra (Barcelona), Spain

${ }^{l}$ Clermont Université, Université Blaise Pascal, Laboratorie de Photochemie Moléculaire et Macromoléculaire (LPMM), BP10448,

F-63000 Clermont-Ferrand, France

${ }^{m}$ CNRS, UMR6505, LPMM, F-63177, Aubiére, France

${ }^{n}$ Condensed Matter Physics, Brookhaven National Lab, Building 510B Upton, NY, 11973, USA
} 


\section{Introduction}

Organic photovoltaics (OPV) constitute an attractive alternative to silicon-based solar cells, manifested in fast processing and extremely low cost. ${ }^{1-3}$ The OPV research field has vastly increased in the past decade, covering a large number of focus areas such as photoelectric conversion efficiency (PCE), processing techniques, new materials, device configuration, and lifetime and stability. Exceptional progress has been made within PCE optimization and lifetime and stability. The PCE is $\sim 10 \%$ for small laboratory cells ${ }^{4,5}$ and $\sim 2 \%$ for roll-to-roll (R2R) cells. ${ }^{6}$ The lifetime has been optimized from minutes to a few years under outdoor conditions. Lifetime and stability are determined by the magnitude and multitude of degradation mechanisms occurring throughout the OPV device during operation and storage. ${ }^{7-9}$ A detailed understanding of the degradation mechanisms is of utmost importance if acceptable lifetimes are to be achieved, which is a prerequisite for largescale application and thus commercialization. ${ }^{3} \mathrm{OPV}$ degradation is highly complex and constitutes an analytical challenge due to the multitude of materials, interfaces, and device architectures that are constantly being modified and optimized..$^{10-13}$

The work presented in this article is part of a large interlaboratory study that resulted from the 3rd International Summit on Organic Photovoltaic Stability (ISOS-3). ${ }^{14}$ The collaboration involved six laboratories (Table 1) capable of manufacturing OPV devices, which produced seven distinct sets of OPV devices. The devices were all shipped to Risø DTU where they were degraded under identical well-defined conditions. Three different degradation conditions were used in accordance with the ISOS-3 protocols: accelerated full sun simulation; low level indoor fluorescent lighting; and dark storage with daily monitoring of the photovoltaic parameters. ${ }^{14}$ These conditions will be referred to as "full sun", "fluorescent" and "dark", respectively. The devices were analyzed and characterized at different points of their lifetime by a large number of non-destructive and destructive techniques. The terminology used for a lifetime of a device extracted from the degradation experiment is "TXX", where XX denotes the percentage which the PCE has declined to from the initially measured PCE, i.e. T100 is the initial measurement, T80 is when PCE has declined to $80 \%$ of its initial value etc. The original goal was to extract the devices from the degradation experiment at $\mathrm{T} 100, \mathrm{~T} 80$, $\mathrm{T} 50$, and $\mathrm{T} 10$, which more or less was achieved (some devices never reached T10 within the timeframe of the project). Once a device was extracted it was not reused, and since some of the characterization methods are destructive, it was necessary to manufacture a large number of devices. The degradation experiments lasted up to 1830 hours and involved more than 100 devices with more than 300 cells (a device can contain several cells).

The ISOS-3 inter-laboratory study has produced a vast amount of results, which so far has resulted in three articles, hereafter termed ISOS-3 reports. ${ }^{15-17}$ The different device manufacturing methods along with the degradation procedures and electrical characterization have been presented in the first ISOS-3 report. ${ }^{15}$ The second ISOS-3 report describes work using a suite of imaging techniques to map specific degradation mechanisms. ${ }^{16}$ The following imaging techniques were employed: laser-beam induced current (LBIC), photoluminescence imaging (PLI), electroluminescence imaging (ELI) and lock-in thermography (LIT). In addition to analyzing the ISOS-3 devices at specified T-values (in this case corresponding to different devices and thus cells), selected devices were cycled in order to monitor the evolution of spatial defects on the same cell. In the third article incident photon-to-electron conversion efficiency (IPCE) and in situ IPCE were employed to describe various degradation mechanisms. ${ }^{17}$ The most important conclusions regarding degradation mechanisms based on the previous ISOS-3 reports are summarized in the following.

The combination of the imaging techniques LBIC, PLI, ELI and LIT suggested that the main degradation mechanisms were the following: ${ }^{16}$

- Formation of aluminium oxide (at the aluminium electrode).

- Formation of blocking contacts due to silver oxide formation or $\mathrm{ZnO}$ dedoping.

- Electro-migration of silver (especially at the edges due to enhanced electric fields).

- Water and oxygen ingress through pinholes and from the edges of the cells.

- Water release from highly conductive PEDOT:PSS.

The overall conclusion based on the imaging results is that OPV device stability is mostly controlled by the instability of the charge collecting electrodes. It should be emphasized that these imaging analyses alone do not directly reveal degradation mechanisms, complementary information is often necessary to come to plausible conclusions. Ideally it would make

Table 1 Cell configurations used in the ISOS-3 inter-laboratory study

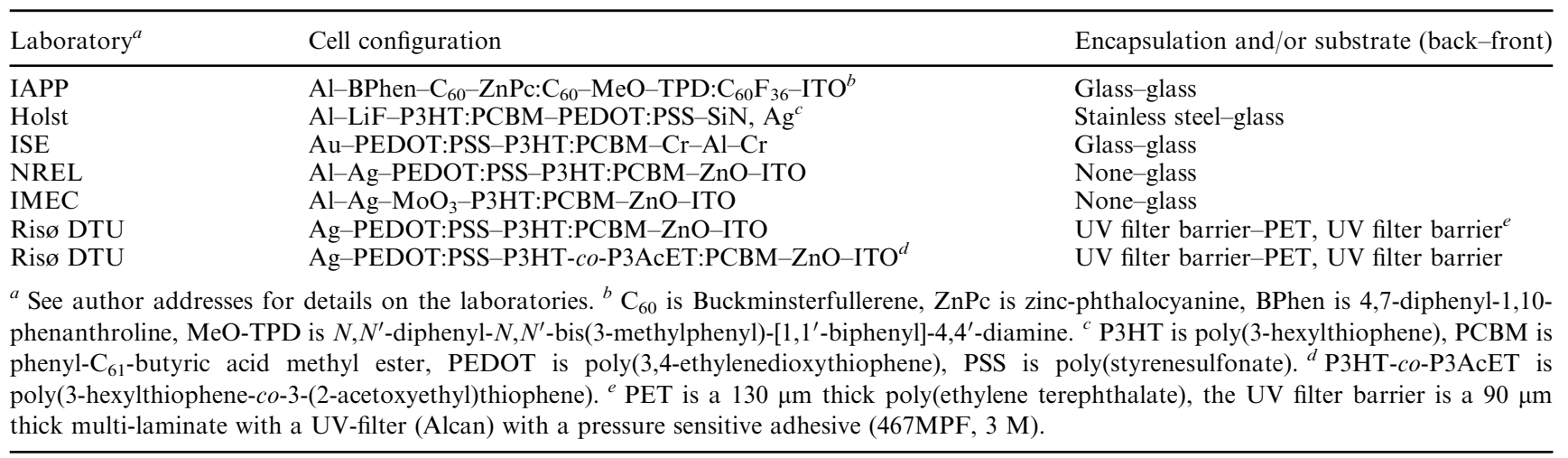


sense to combine the analyses with techniques that produce direct chemical information.

Because the IPCE and in situ IPCE analyses were conducted in both ambient and $\mathrm{N}_{2}$ atmospheres it was possible to identify the materials more susceptible to degradation caused by molecular oxygen and water. The result of the IPCE and in situ IPCE analyses resulted in the following major conclusions/ comments regarding degradation: ${ }^{17}$

- For some of the encapsulated devices the degradation could possibly be initiated at the $\mathrm{Ag}$ or $\mathrm{Au} / \mathrm{PEDOT}$ :PSS interface by the formation of a chemical bond between the $\mathrm{Ag}$ (or $\mathrm{Au}$ ) and the PEDOT:PSS, which can occur in the absence of oxygen and water.

- The devices without encapsulation were highly dependent on atmospheric conditions and water uptake was a major problem attributed to the hygroscopic nature of PEDOT:PSS and semiconductor oxides.

- For the devices without encapsulation the water uptake was observed to be random and reversible.

- For the devices without encapsulation water will primarily degrade the electrodes of the cell.

- The cells within a device (a device can contain several cells) degraded differently depending on the position of the cell in the device.

The present work constitutes the fourth and final report in the series of reports that resulted from the ISOS-3 interlaboratory study. The main analytical technique used in this work is time-of-flight secondary ion mass spectrometry (TOFSIMS), a technique producing direct chemical information. The secondary technique is X-ray photoelectron spectroscopy (XPS), which also produces direct (but complementary) chemical information. The basic information of TOF-SIMS is mass spectral information, i.e. chemical information. TOFSIMS imaging has an exceptional low probe depth of 1-2 nm, and is able to obtain surface images based on the mass spectral information. Furthermore, material can be sputtered away from the surface during the TOF-SIMS imaging analysis, i.e. a microscopic hole can be made that when combined with the imaging capability produces a depth profile, i.e. mass spectralbased images as a function of depth. The principle of TOFSIMS depth profiling is schematically shown in Fig. 1. The fact that TOF-SIMS produces direct chemical information from any given point in the cell makes it, in principle, an ideal technique to either directly identify a degradation mechanism,

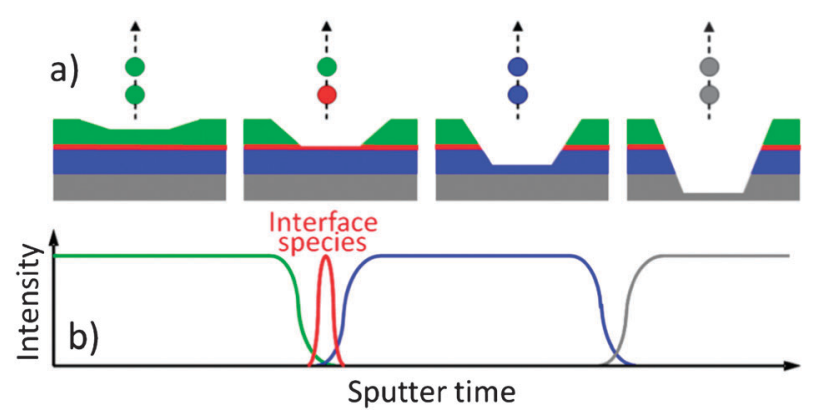

Fig. 1 (a) Schematic cross-section of an OPV device at various stages of depth profiling. (b) Schematic depth profile showing the intensity of various materials as a function of sputter time (i.e. depth). or complement the analysis results described in the previous ISOS-3 reports. ${ }^{15-17}$ However, there are certain limitations such as a poor depth resolution, which makes it challenging to detect interface phenomena. Furthermore, the depth profiling properties used are such that all molecular information is destroyed leaving only atomic ions and small fragment ions to be monitored. Finally, the data interpretation can be very challenging due to the enormous amount of mass spectral peaks generated during a TOF-SIMS analysis, which is problematic if one does not know specifically what one is looking for, i.e. "looking for a needle in a haystack situation".

The main focus of the work presented herein is to study the degradation of the active bulk material monitored by the oxygen incorporation that will be correlated with loss in performance for the various ISOS-3 devices. Furthermore, the oxygen incorporation will be quantified by correlating the TOF-SIMS results with results obtained by the quantitative XPS technique. Furthermore, degradation mechanisms suggested in the previous ISOS-3 reports will be correlated with information extracted from the TOF-SIMS depth profiling analyses. Finally, trends between loss in cell performance and information extracted from the TOF-SIMS depth profiling data will be described and discussed.

\section{Experimental}

Experimental details pertaining to manufacture of the ISOS-3 devices, the degradation experiments, and characterization of the photovoltaic parameters can be found in the first ISOS-3 report. ${ }^{15}$ Relevant information regarding the present work is that seven distinct device types (Table 1) were degraded under three different conditions: full sun, fluorescent, and dark (as mentioned previously in the text). The devices were extracted from the degradation tests at different lifetimes corresponding to (more or less) T100, T80, T50 and T10, and subsequently shipped to the participating laboratories around the world for analysis. The destructive analyses were obviously performed last and when Risø DTU (that initially performed the degradation experiments) received the devices for the destructive TOF-SIMS analysis, they were placed in a glove box in a dry nitrogen atmosphere. Devices that were encapsulated had the encapsulation removed. A TOF-SIMS depth profiling analysis cannot penetrate the thick encapsulation. The Risø DTU cells were laminated and when delaminated the layers detached at the PEDOT:PSS/P3HT:PCBM interface, which turned out to be fortunate (will be evident later in the text). The devices and partial devices were placed on a TOF-SIMS sample holder in the glove box that was then placed in a specially designed transfer vessel that can sustain a controlled atmosphere long enough for the transfer vessel to be inserted into the vacuum chamber of the TOF-SIMS instrument. The encapsulated devices were thus never exposed to ambient air between the degradation experiments and the TOF-SIMS analysis. After the TOF-SIMS analysis the devices were transferred back to the glove box and stored until possible reanalysis.

TOF-SIMS analyses were performed on six out of the seven distinct devices. The IAPP device was omitted since the main objective in this study was to compare the oxygen incorporation in the active material as a function of loss in performance. 


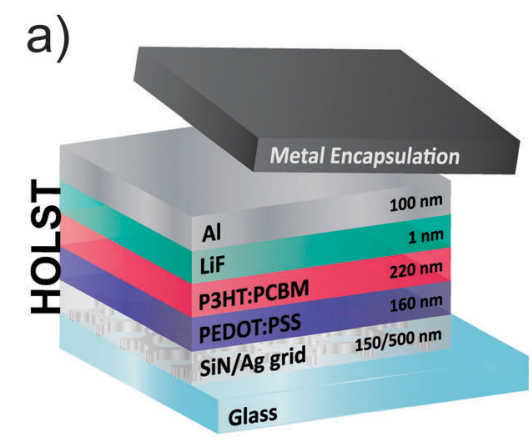

d)

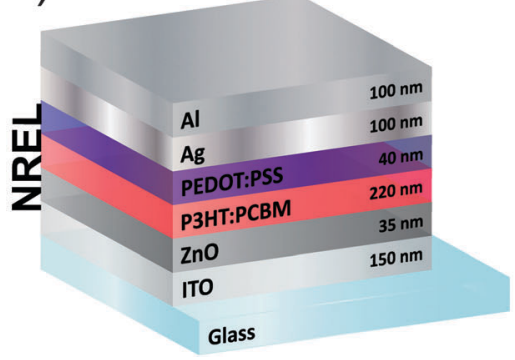

b)

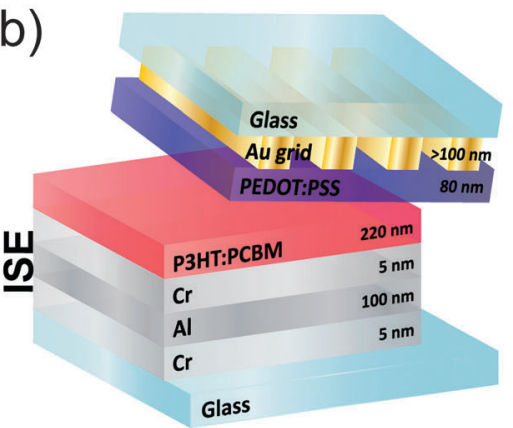

e)

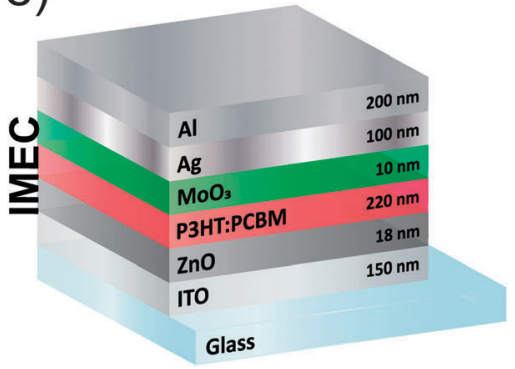

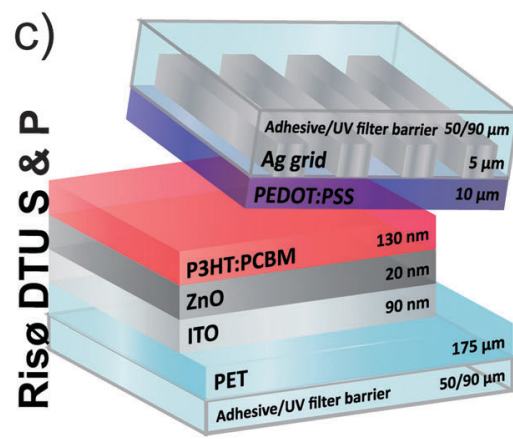

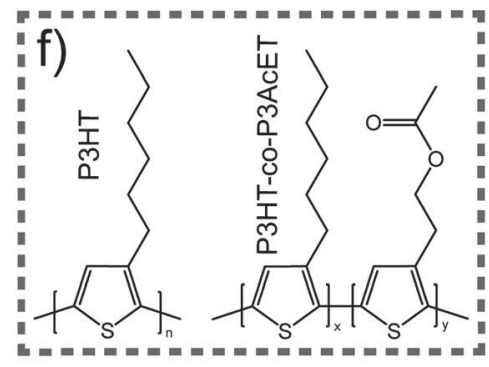

Fig. 2 (a)-(e) illustrate the different device layer structures (materials and thicknesses) investigated in this work. The tilted sections on devices (a)-(c) indicate where the devices were opened/delaminated, thus making the TOF-SIMS analysis possible. The active layers of all the devices consisted of P3HT:PCBM except the Risø DTU S device that had the slightly modified P3HT polymer P3HT-co-P3AcET. The molecular structures of P3HT and P3HT-co-P3AcET are shown in (f).

The IAPP device is the only device not using P3HT:PCBM as the active material. The intensity of a mass spectral marker can only be compared for the same material when different cells are compared due to the response factors that are material dependent in a TOF-SIMS analysis. Another problem with the IAPP device was the long lifetime that by far exceeded the 1830 hours that the degradation experiments lasted. However, the IAPP device has previously been extensively studied at Risø DTU. ${ }^{18}$ In that particular study the device was exposed to controlled atmospheres without encapsulation and illuminated (AM1.5G, $330 \mathrm{~W} \mathrm{~m}^{-2}$, $49{ }^{\circ} \mathrm{C}$ ). T50 was found to be $\sim 2700$ hours in a $\mathrm{N}_{2}$ atmosphere, 74 hours in an $\mathrm{O}_{2}: \mathrm{N}_{2}$ atmosphere, and 11 hours in a $\mathrm{H}_{2} \mathrm{O}: \mathrm{N}_{2}$ atmosphere. It was found that water significantly causes the device to degrade. The two most significant water-induced degradation mechanisms were found to be: (i) diffusion of water through the aluminium electrode in between the grains, resulting in formation of aluminium oxide at the BPhen/Al interface, and (ii) diffusion of water into the active layer $\left(\mathrm{ZnPc}: \mathrm{C}_{60}\right)$, where $\mathrm{ZnPc}$, but not $\mathrm{C}_{60}$, becomes oxidized. Fig. 2 shows schematics of the devices that were studied in this work, and associated layer thicknesses.

\subsection{TOF-SIMS analysis}

The TOF-SIMS analyses were performed using a TOF-SIMS IV (ION-TOF GmbH, Münster, Germany). 25 ns pulses of $25 \mathrm{keV} \mathrm{Bi}^{+}$(primary ions) were bunched to form ion packets with a nominal temporal extent of $<0.9 \mathrm{~ns}$ at a repetition rate of $10 \mathrm{kHz}$, yielding a target current of $0.7 \mathrm{pA}$. These primary ion conditions were used to obtain mass spectra, ion images, and depth profiles. Depth profiling was performed using an analysis area of $200 \times 200 \mu \mathrm{m}^{2}$ centred in a sputter area of

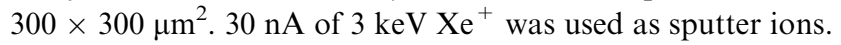

An encapsulated IMEC device was analyzed in a slightly different way: the encapsulation was removed and the $\mathrm{Al}-\mathrm{Ag}-\mathrm{MoO}_{3}$ stack was partly removed. $11 \times 8 \mathrm{~mm}^{2}$ surface areas were then imaged, each covering four cells on the device. These images were cropped to sizes corresponding to the individual cells $\left(5.2 \times 2.7 \mathrm{~mm}^{2}\right)$. Depth profiling was performed on the encapsulated IMEC device at various surface locations using an analysis area of $500 \times 500 \mu^{2}$ centred in a sputter area of $750 \times 750 \mu \mathrm{m}^{2}$. For all analyses electron bombardment $(20 \mathrm{eV})$ was used to minimize charge built-up at the surface. Desorbed secondary ions were accelerated to $2 \mathrm{keV}$, mass analyzed in the flight tube, and post-accelerated to $10 \mathrm{keV}$ before detection.

The relative degree of oxygen incorporation (i.e. degradation) in the bulk active material is extracted from the depth profiling data by evaluating the depth profiles in order to pinpoint the sputter time window that corresponds only to the bulk P3HT:PCBM material. This is exemplified by the NREL device that exhibits illustrative depth profiles (Fig. 3) that demonstrate the principle.

Careful selection of more or less specific mass spectral markers enables distinction between the individual layers. Within the sputter time window for the P3HT:PCBM material the goal was to pinpoint where all the signal intensities are constant/parallel, i.e. without interference from other species. The oxygen depth profile $\left(\mathrm{O}^{-}\right)$in Fig. 3 shows that in that particular case there is only a limited sputter time window available due to interference from $\mathrm{ZnO}$ and ITO that contributes to the oxygen depth profile $\left(\mathrm{O}^{-}\right)$. In this case the interference is probably caused by a small degree of interlayer mixing, which is not caused by the sputter process that acts in the opposite direction. Furthermore, a depth profile only makes physical sense if the lateral plane of the probed volume is homogeneous, so to ensure lateral homogeneity the ion 


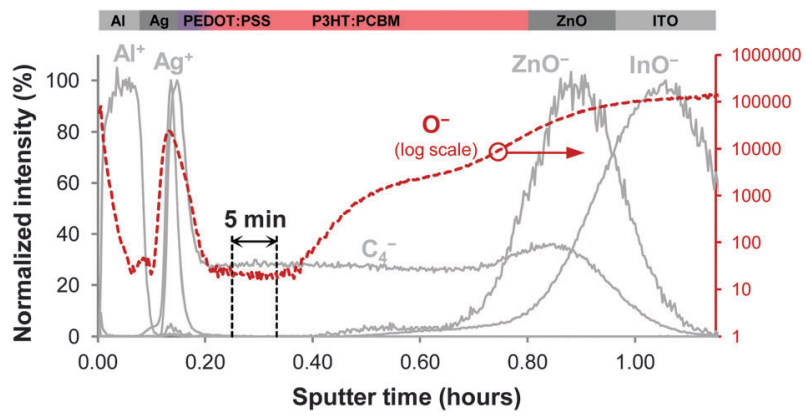

Fig. 3 TOF-SIMS depth profiles of a T100 NREL device (the layer structure is indicated at the top of the figure). Various carefully selected mass spectral markers identify the different layers (grey lines). The oxygen profile (dashed red line) and the indicated sputter time window corresponding to the bulk of the P3HT:PCBM material show from where the information is extracted. The thin PEDOT:PSS layer is defined by the $\mathrm{Na}^{+}$profile (not shown) and does not overlap with the 5 minute sputter time window in question.

images were carefully analyzed and any abnormalities such as spatially localized contaminants (e.g. particles) were bypassed in the dataset, which ensured that only the photo-oxidation was probed. The depth profiles in Fig. 3 also demonstrate the unfortunate poor depth resolution that worsens for longer sputter times. It should be emphasized that different materials have different sputter rates, so there is no correlation between relative sputter time windows and relative layer thicknesses. To ensure that the extracted information could be compared within and across the different devices some simple measures had to be taken during the data interpretation. It is not a problem to maintain the experimental analysis conditions over short periods of time, however, due to the large amount of devices that were analyzed over a very long time it was impossible to reproduce the experimental conditions accurately. The signal intensity is sensitive towards some instrumental parameters, so in order to eliminate the instrument effects and maintain the comparability the following procedure was adapted: in each case equally sized sputter time windows corresponding to 30 scans were chosen. More importantly, the oxygen signal intensity was normalized against the sum of most of the abundant signals within the same sputter time window, which constituted (for the sputter conditions in question) the following signals: $\mathrm{C}_{n}{ }^{-}(n=2-4 ; 6-10)$. The peak $\mathrm{C}_{5}{ }^{-}$was omitted due to significant peak overlap and $\mathrm{C}_{1}{ }^{-}$was omitted because it, for unknown reasons, worsened the reproducibility. It was thus $\operatorname{Int}\left(\mathrm{O}^{-}\right) / \operatorname{Int}\left(\mathrm{C}_{n}{ }^{-}, n=2-4 ; 6-10\right)$ that was extracted from each depth profile (the ratio was multiplied by a factor of 1000 for practical reasons), which provides a semi-quantitative measure of the relative oxygen incorporation in the active layer for various devices at different lifetimes (T100, T80, T50, T10).

\subsection{XPS analysis}

XPS was employed to convert the semi-quantitative TOFSIMS information into quantitative XPS information by correlating XPS data with TOF-SIMS data, i.e. creating a calibration curve. The XPS analyses were performed on a K-alpha (Thermo Electron Limited, Winsford, UK) using a monochromatic Al- $\mathrm{K}_{\alpha}$ X-ray source and a take-off angle of $90^{\circ}$ from the surface plane. Atomic concentrations were determined from surface spectra $(100-600 \mathrm{eV}, 200 \mathrm{eV}$ detector pass energy, 5 scans) and were calculated by determining the relevant integral peak intensities using a Shirley type background. All XPS analyses were repeated at least three times on different surface locations.

\section{Results and discussion}

\subsection{Quantification of TOF-SIMS depth profiling data}

When studying oxygen incorporation/uptake in P3HT:PCBM (i.e. degradation) it is obviously interesting to attempt to quantify how much oxygen is incorporated. This turned out to be far from simple. The first approach was to create a series of calibration samples from which a calibration curve could be obtained. P3HT:PCBM was spin-coated onto ITO-coated glass substrates (ITO improved the quality of the mass spectral peak shapes) and illuminated for varying amounts of time. The idea was then to perform non-quantitative TOF-SIMS depth profiling on these calibration samples, extract the normalized oxygen intensities and then perform quantitative XPS depth profiling on the same samples, and subsequently correlate the data. This was, however, not possible because during the XPS depth profiling analysis the oxygen becomes underestimated due to a sputter phenomenon. The same phenomenon applies for the TOF-SIMS depth profiling but that is of less importance since TOF-SIMS is not quantitative to start out with, the only effect is a decrease in sensitivity towards oxygen during TOF-SIMS depth profiling. This problem was solved by performing XPS spectroscopy directly on the surfaces (i.e. not depth profiling) of the calibration samples and correlating these results with the TOF-SIMS depth profiling data. This is only justified because the surface chemistry appears to be equivalent with the bulk chemistry (often not the case), which is documented in Fig. 4 for a spin-coated P3HT:PCBM sample. As is evident from Fig. 4 all the profiles

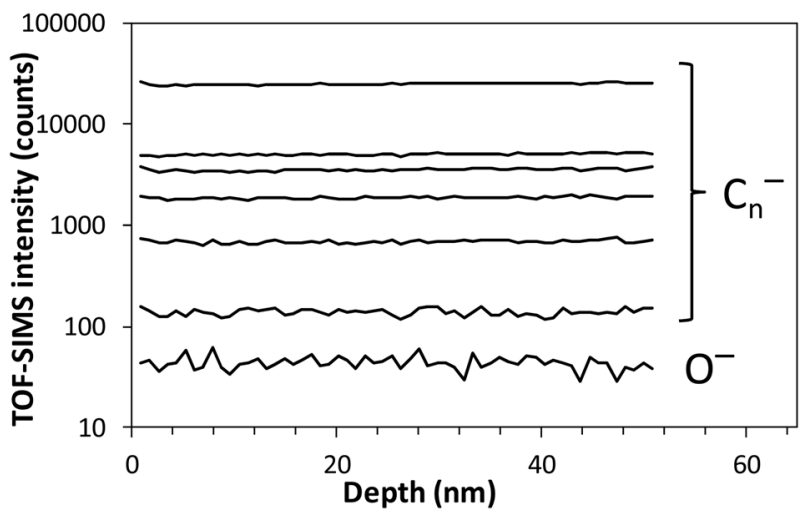

Fig. 4 TOF-SIMS depth profiles of a spin-coated P3HT:PCBM sample. The sample was spun from dichlorobenzene $\left(20: 20 \mathrm{mg} \mathrm{ml}^{-1}\right)$ at $800 \mathrm{rpm}$ for one minute producing a $208 \pm 3 \mathrm{~nm}$ film thickness (measured by AFM profilometry). The sputter process is in increments of $10 \mathrm{~s}$ using $3 \mathrm{keV}$ $\mathrm{Xe}^{+}(30 \mathrm{nA})$ over a $300 \times 300 \mu \mathrm{m}^{2}$ surface area and the analysis covers the central $200 \times 200 \mu \mathrm{m}^{2}$ part using $0.7 \mathrm{pA} \mathrm{Bi}^{+}$. The sputter time scale was converted to a depth scale from a measured sputter rate of $5.26 \pm 0.08 \mathrm{~nm} \mathrm{~min}^{-1}$ (only valid for P3HT:PCBM). 
have a constant intensity from the first scan, which suggests that the surface chemistry in this case is equivalent to the bulk chemistry. It is therefore justified to correlate surface obtained XPS data with bulk obtained TOF-SIMS data.

The second problem was caused by a well-described phenomenon. P3HT has the ability to interact with molecular oxygen resulting in the formation of a charge transfer complex (eqn (1)). ${ }^{19-21}$ The process is reversible and is thus sometimes referred to as reversible degradation:

$$
\mathrm{P} 3 \mathrm{HT}+\mathrm{O}_{2} \rightleftarrows\left[\mathrm{P} 3 \mathrm{HT}^{\delta+} \ldots{ }^{\delta-} \mathrm{O}_{2}\right]
$$

Abdou et al. ${ }^{19}$ described the phenomenon for poly(3-alkylthiophenes) and found that $\sim 1 \%$ of the $\pi$-conjugated segments and $\sim 30 \%$ of the dissolved molecular oxygen form a charge transfer complex, which corresponds to a charge transfer complex concentration of $\sim 1.3 \times 10^{-3} \mathrm{M}$. They found that the complex is weakly bound $\left(\Delta H^{\circ}=-10.6 \mathrm{~kJ} \mathrm{~mol}^{-1}\right)$ and possesses a distinct absorption band in the visible region. The electronic properties of the material are affected by the complex depending on the oxygen pressure. The authors found that the complex causes the carrier concentration to increase, the conductivity to increase, and the charge carrier mobility to be lowered, and the complex is a fluorescence quencher of mobile polaronic excitons.

In a recent publication Guerrero et al. ${ }^{20}$ studied the phenomenon in OPV devices with the configuration $\mathrm{Ag}-\mathrm{Ca}-$ P3HT:PCBM-PEDOT:PSS-ITO. The authors showed that the complex is present in complete cells and that it is responsible for photocurrent reduction and loss in photo-voltage. Furthermore, it was found that irreversible degradation induced by molecular oxygen is attributed to calcium oxide formation.

Aguirre et al. $^{21}$ demonstrated that illuminating P3HT in the presence of air induces persistent radical cations on the P3HT chains. They found that the photo-induced charges are stable at room temperature for several hours, but recombine quickly if the air is removed from the atmosphere. The authors postulate, that the persistency of the photo-induced charges is possible due to the existence of an energy barrier separating the excited charge transfer state from the ground state charge transfer complex. The barrier is proposed to be a result of stabilization of the excited charge transfer state and possibly a result of chemical interaction between $\mathrm{P} 3 \mathrm{HT}$ and molecular oxygen, resulting in a so-called relaxed charge transfer state. Finally, it was found that lowering the pressure of air in the chamber was sufficient to break up the charge pair.

In the present work the afore-mentioned calibration samples were spin-coated in ambient air and stored for $\sim 20$ hours in darkness in ambient air before being transferred to the vacuum chambers of the TOF-SIMS and XPS instrument. It became evident that the charge transfer complex had to be considered.

When extracting the normalized oxygen intensities from the calibration samples an effect of time was observed. This is demonstrated in Fig. 5 for various spin-coated P3HT:PCBM samples exposed to various experimental conditions. All samples exhibit the same behaviour, which is a decrease in normalized oxygen intensity (oxygen content in the material, i.e. not in the gas phase) as a function of time. This phenomenon is not

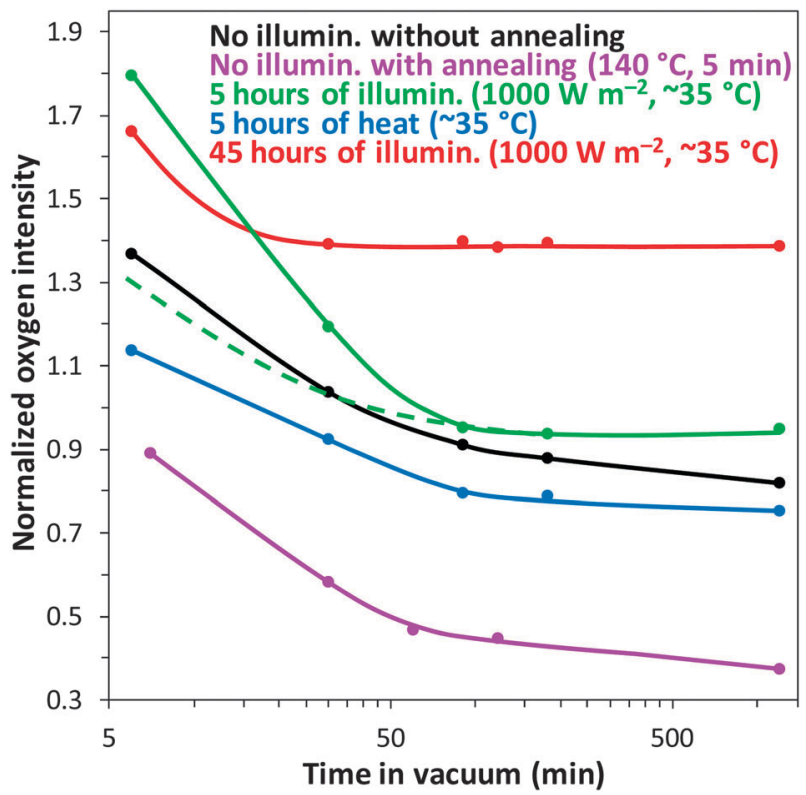

Fig. 5 Normalized oxygen intensity of the film as a function of time in vacuum for spin-coated P3HT:PCBM films. The probe depth was $\sim 25 \mathrm{~nm}$. The samples were spun from dichlorobenzene (20:20 mg ml${ }^{-1}$ ) at $800 \mathrm{rpm}$ for one minute. All illuminated samples were not annealed prior to illumination. The normalized oxygen intensity was extracted from TOF-SIMS depth profiles as described earlier in the text. All samples were introduced into the vacuum chamber approximately 20 hours after spin coating. It took 3 minutes to pump down and an additional 3 minutes to set up the analysis before data could be collected. The green dashed line indicates the sample that is illuminated for 5 hours and then reanalyzed after storing in darkness in ambient air.

related to simple diffusion of solubilized molecular oxygen out of the material, which is a process that takes place within a few minutes at the most. It is presumably an effect of the reversible formation of the charge transfer complex (eqn (1)). Once the samples are placed in a vacuum the equilibrium follows Le Chatelier's principle and shifts towards removal of molecular oxygen from the complex, i.e. depletion of the charge transfer complex.

The plots in Fig. 5 contain a lot of interesting information. If the result obtained for the non-annealed non-illuminated sample (black line) is compared with the annealed non-illuminated sample (purple line), it is clear that a significant drop is observed in the normalized oxygen intensity. This has been confirmed by XPS that shows a 30\% drop in oxygen content. Furthermore, it is consistent with the findings by Mattis et $a .^{22}$ that concluded that an annealing temperature above $120{ }^{\circ} \mathrm{C}$ is required to promote oxygen desorption. The sample that was heated for five hours (blue line) was put under the simulated sun wrapped in aluminium foil so that it would receive the heat $\left(\sim 35^{\circ} \mathrm{C}\right)$ but not the light. Five hours at $\sim 35^{\circ} \mathrm{C}$ must be considered as a very gentle annealing compared to five minutes at $140{ }^{\circ} \mathrm{C}$ (purple line), which is consistent with the relative result observed in Fig. 5. For the illuminated samples (green and red lines) a significant increase in normalized oxygen intensity is observed. The illumination promotes the generation of the persistent radicals enabling the charge 
transfer complex to be formed, which partly explains the elevated normalized oxygen intensities. In addition, the harsh conditions will inevitably photo-oxidize the material forming covalently bound degradation products, i.e. an irreversible process. It appears that the more the photo-oxidation present the shorter the time to level out, i.e. faster depletion of the charge transfer complex. This is intuitively what one would expect based on the fact that photo-oxidation reduces the number of molecular sites available for charge transfer complex formation. The sample that had undergone the following procedure: stored in darkness for $\sim 20$ hours, illuminated for five hours, stored in darkness for $\sim 20$ hours, analyzed, stored in darkness for $\sim 20$ hours, reanalyzed, correspond to the solid green and dashed green lines, respectively (Fig. 5). The reanalyzed sample has an initial value that is significantly lower compared to the first time it was analyzed, but levels out to the photo-oxidation level that was also observed during the first analysis. This observation suggests that once the material has been depleted for the charge transfer complex it requires light to restore it to the original charge transfer complex concentration. Assuming that the plots in Fig. 5 were correctly interpreted, it means that the charge transfer complex is formed to some degree without illumination or, alternatively, because the samples unavoidably received some degree of low level illumination during handling. The findings presented in Fig. 5 agree fairly well with what has been described in regard to the charge transfer complex using alternative techniques. ${ }^{19-21}$ However, the timescale for depletion of the charge transfer complex in a vacuum is somewhat surprising and unpractical.

A calibration curve could now be constructed based on samples that were stored in the XPS and TOF-SIMS vacuum chambers for at least 20 hours prior to analysis in order to remove/minimize the charge transfer complex to an acceptable degree (not shown). At this point the third problem revealed itself. The calibration curve (not shown) produced unrealistic results when applied to the ISOS-3 depth profiling results. After numerous systematic experiments it became clear that annealing had a crucial effect on the calibration curve, more precisely on the normalized oxygen intensities obtained by TOF-SIMS, which is presumably a matrix effect caused by the annealing that presumably changes the crystallinity. All the ISOS-3 devices were annealed during fabrication, which therefore requires calibration samples that are annealed under the same conditions. The TOF-SIMS depth profiling results are clearly very sensitive to experimental conditions, which raised some concern about whether the fact that the calibration samples were exposed to ambient air during illumination could have an effect, i.e. the P3HT:PCBM material in the ISOS-3 devices was sandwiched between various barrier layers and electrodes. Due to the clearly complex nature of these calibration experiments an alternative (more safe) approach was chosen that was simpler but rougher. It was decided to use some of the ISOS-3 cells that were stored in darkness in a glove box after the degradation experiments and analyses. Since XPS depth profiling was not an option (discussed earlier in the text) the choice of cells was limited to those that were delaminated, i.e. with the P3HT:PCBM exposed (Fig. 2). The ISE and the Risø DTU cells fulfilled this criterion.

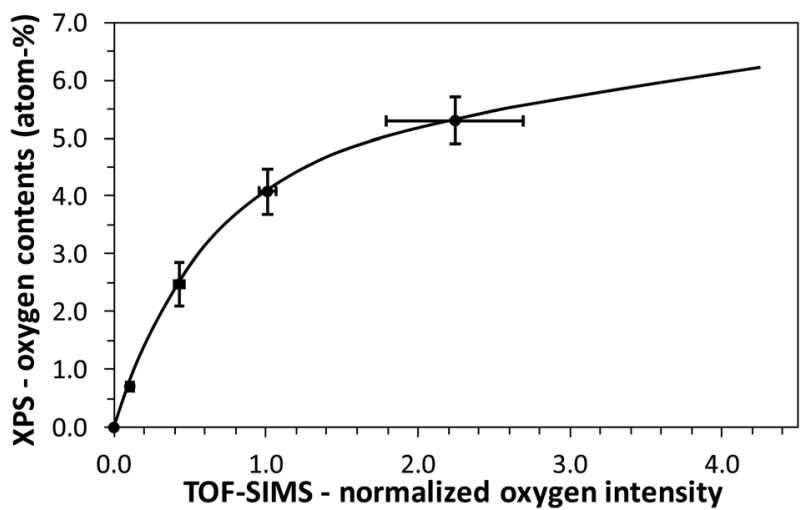

Fig. 6 Calibration curve between TOF-SIMS depth profiling data and XPS data. The TOF-SIMS data were normalized from $\operatorname{Int}\left(\mathrm{O}^{-}\right) /$ $\operatorname{Int}\left(\mathrm{C}_{n}{ }^{-}, n=2-4 ; 6-10\right)$ and multiplied by a factor of 1000 for practical reasons. Each point is an average of at least three points on different surface locations. All samples were placed in the vacuum chamber at least 20 hours prior to analysis in order to remove the weakly bound charge transfer complex between molecular oxygen and P3HT. The probe depth was $\sim 25 \mathrm{~nm}$.

The ISE was encapsulated with glass during the degradation experiments, so it is expected to have experienced a minimum of oxygen incorporation or none at all. The Risø DTU cells were encapsulated with a semi-impermeable organic barrier film, which previously was shown not to be $100 \%$ efficient. ${ }^{30}$ Risø DTU T100 and T10 cells (full sun) were used for the calibration curve. The cells were stored at least 20 hours in the vacuum chambers of the TOF-SIMS and XPS instruments prior to analysis. The calibration curve is shown in Fig. 6.

It is very fortunate that a modified version of P3HT (P3HTco-P3AcET:PCBM) is used in the Risø DTU S device as it contains native oxygen in the form of an ester group (Fig. 2f) that will help spread the points in the calibration curve. The lowest point is obviously $(0.0)$ and the highest point is $(2.2,5.3)$ that originates from the Risø DTU S T10 cell, so any measurements acquired above this value will be based on extrapolation.

The need for storing the samples for at least 20 hours in the TOF-SIMS vacuum chambers prior to analysis was realized after all the ISOS-3 devices were analyzed, which obviously raised some concern. However, upon further reflection it turned out not to be a problem. All the glass/metal encapsulated cells were never exposed to ambient air at any point, so there is no concern about oxygen uptake. The Risø DTU cells were exposed to oxygen and water to some extent due to inferior encapsulation, and the non-encapsulated were obviously directly exposed to ambient air during the degradation experiments and during the non-destructive analysis in the various laboratories. After testing they were all sent back to Risø DTU and placed in a glove box. The devices were then prepared for analysis (removal of encapsulation) and 13-18 samples were placed on the TOF-SIMS sample holder, a procedure that took most of a day. The sample holder was then typically transferred via a transfer vessel containing an inert atmosphere to the TOF-SIMS analysis chamber late in the day so that it would be ready for analysis the next morning. So by tracing back the working procedures it could be concluded that all the ISOS-3 devices were exposed to the nitrogen atmosphere in the 
glove box and the vacuum in the TOF-SIMS instrument for such a long time that it is safe to assume that the charge transfer complex had been depleted.

\subsection{Oxygen incorporation and its effect on device degradation}

It should be clear by now that oxygen incorporation in P3HT:PCBM is described by two processes: (i) formation of a charge transfer complex (reversible degradation), and (ii) photooxidation (irreversible degradation). Both processes are well-described in the literature and constitute an analytical challenge when present at the same time. However, due to the fortunate timescale of the analyses of the ISOS-3 devices we can assume that only irreversible photo-oxidation is probed. P3HT and P3HT:PCBM are well-described in terms of photooxidation both as materials but also as components in photovoltaic devices. In this study photo-oxidation of the active materials in the ISOS-3 devices was quantified using XPS calibrated TOF-SIMS depth profiling data, which has never been attempted before.

Photo-oxidation of the active material (P3HT:PCBM) was then compared to loss of photovoltaic performance, which is not necessarily an easy comparison since other degradation mechanisms are in play. The ultimate challenge in studying degradation phenomena in OPV devices is to quantify the contribution from each degradation mechanism to the overall degradation of the photovoltaic performance.

In terms of photo-oxidation it makes sense to group the six different devices (Table 1 and Fig. 2) according to the encapsulation, well-knowing that we thereby do not consider possible internal photo-oxidation caused by metal oxides. The encapsulation used can be split up into three groups: (i) glass/ metal encapsulation (ISE and Holst), (ii) UV filter (flexible) encapsulation (Risø DTU S and P), and (iii) non-encapsulated (IMEC and NREL). The groups are listed here according to permeability with respect to molecular oxygen and water.

3.2.1 Comments on reproducibility for devices and TOFSIMS analyses. As described in the first ISOS-3 report devices were extracted from the degradation experiments at various degrees of performance, more or less corresponding to T100, T80, T50, and T10. ${ }^{15}$ Because some of the analyses were destructive it was not possible to follow loss of performance from the beginning to the end for one particular device, it had to be four devices that each represented T100, T80, T50, and $\mathrm{T} 10$, respectively. However, this will consequently result in strict requirements in terms of reproducibility when manufacturing the devices, which seems challenging considering the delicate device architectures requiring multiple processes to finally become a device. This was clearly seen in the third report that focused on IPCE analyses revealing significant differences in IPCE between equivalent devices and between cells in a device/module. ${ }^{17}$

Oxygen incorporation in the active material is expected to be zero or close to zero in the impermeable encapsulated devices and modest in the others according to previous experience. $^{29}$ Furthermore, the sputter process reduces the sensitivity profoundly, so detecting small changes with inferior sensitivity requires a good reproducibility with respect to device manufacturing since aberrations will result in chemical
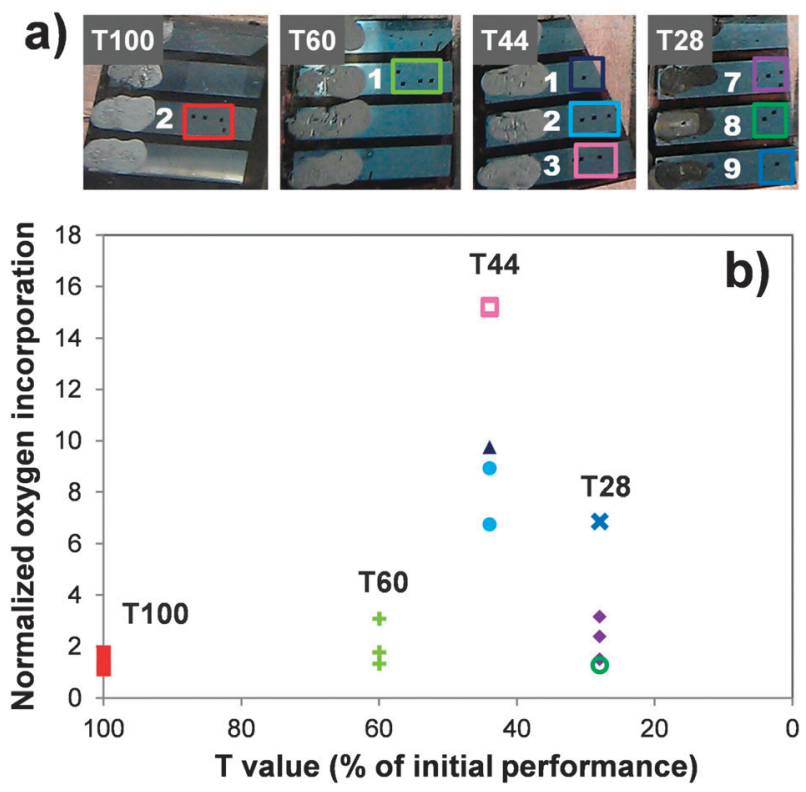

Fig. 7 (a) Photographs of pieces of IMEC devices (full sun) showing the TOF-SIMS depth profiling holes. The devices were cut in pieces so that they could be analyzed using various destructive methods. The colored squares indicate which analyses were associated with this test. (b) Normalized oxygen incorporation corresponding to cell surface locations shown in (a) as a function of performance loss. The TOFSIMS data were normalized from $\operatorname{Int}\left(\mathrm{O}^{-}\right) / \operatorname{Int}\left(\mathrm{C}_{n}^{-}, n=2-4 ; 6-10\right)$ and multiplied by a factor of 1000 for practical reasons.

inhomogeneities that will consequently affect the relative results and thus the quality of the work.

In order to assess the reproducibility associated with the ISOS-3 cells a test was performed on four IMEC devices (full sun) corresponding to T100, T60, T44, and T28, respectively (Fig. 7a). Multiple analyses were performed on one single cell, and multiple cells were analyzed within the same device in order to measure the point-to-point variation within the same cell as well as the cell-to-cell variation. The result is shown in Fig. 7.

Several interesting observations can be extracted from Fig. 7. The reproducibility is observed to significantly deteriorate for lower T-values, which suggests that the oxygen incorporation becomes more inhomogeneous for increasing degree of photo-oxidation. In addition, the highest T44 and T28 values originate from the central parts of the devices (not obvious from Fig. 7a), which, however, could be a coincidence considering the limited data. Finally, the result suggests that the cell-to-cell variation is significantly larger than the point-topoint variation on the same cell, which is surprising. No explanation was found for this observation. The magnitude of the relative (reverse) result of the T28 and T44 devices suggested that one of the devices was erroneous somehow. A comparison of the IV degradation characteristics revealed that the T28 IMEC device showed a clear inconsistency and was consequently omitted.

It is obvious from the reproducibility test that a certain degree of noise in the data is expected for especially the low $\mathrm{T}$-value devices due to the fact that an apparent inhomogeneity is introduced for an increased degree of degradation in 
the active material. Inhomogeneous degradation patterns were observed in the work described in the second ISOS-3 report. ${ }^{16}$

3.2.2 Full sun, fluorescent, and dark degradation conditions. After the TOF-SIMS depth profiling analyses were complete the effects in terms of oxygen incorporation were observed to be very subtle for the devices degraded under a full sun, i.e. the harshest condition compared to fluorescent and dark conditions. The results for the fluorescent and dark conditions were therefore, as expected, even more subtle, to a degree where the point-to-point variation caused by the material inhomogeneity is far greater. The following discussion will thus focus on devices degraded under full sun conditions.

3.2.3 Glass/metal encapsulation - ISE and Holst devices. The ISE and Holst devices were encapsulated by glass-glass and glass-metal, respectively, and sealed with epoxy. These two devices thus had so-called impermeable encapsulation, which is expected to reflect in the analysis results. Fig. $8 \mathrm{a}$ and b presents the measured oxygen contents as a function of loss of performance and illumination time for the ISE and Holst devices.

Because of the impermeable encapsulation no oxygen incorporation was expected during the degradation experiments, which is consistent with the fact that no detectable trend is observed in Fig. 8a and b. However, the results are very scattered, which makes it impossible to detect possible subtle trends. The scattered nature of the points in the graphs suggests that the oxygen content to some extent is inhomogeneously distributed in the active material. How is this at all possible? The native oxygen comes exclusively from PCBM. A possible phase separation between P3HT and PCBM seems unlikely and would have to occur on a macroscopic scale, which is unlikely. An alternative explanation could be varying degree of internal oxidation caused by materials already present in the cells, e.g. water residues in the hygroscopic PEDOT:PSS, which then diffuses into the active material and causes oxidation. It is also possible that the excess PSS (always present in PEDOT:PSS) diffuses into the active material and contributes to the oxygen content (PSS contains $-\mathrm{SO}_{3} \mathrm{H}$ groups). The two suggested explanations could possibly explain why the measured average oxygen contents ( $\sim 4$ atom\%) are elevated compared to the calculated values of 2.2 atom $\%$ (ISE) and 2.4 atom\% (Holst). The calculated values are based on the theoretical element compositions and the P3HT:PCBM compositions, which are $1: 0.7$ for the ISE device and $1: 1$ for the Holst device. Since the T100 cells also have $\sim 4$ atom $\%$ oxygen, the phenomena (if the assumption is correct) must have happened in the time window between fabrication and analysis, which corresponded to months.

Fig. 8c shows loss of performance as a function of time (logarithmic time-scale). The ISE device exhibits an exponential decay (or close to within the accuracy) in performance with time, i.e. straight line behaviour on a logarithmic time-scale (Fig. 8c). The Holst device has a non-linear behaviour that suddenly drops significantly after 21 hours, resulting in a relatively low lifetime (T8 after 122 hours). For comparison the ISE device reaches T13 after 1822 hours. It was suggested in one of the earlier ISOS-3 reports that the rapid degradation of
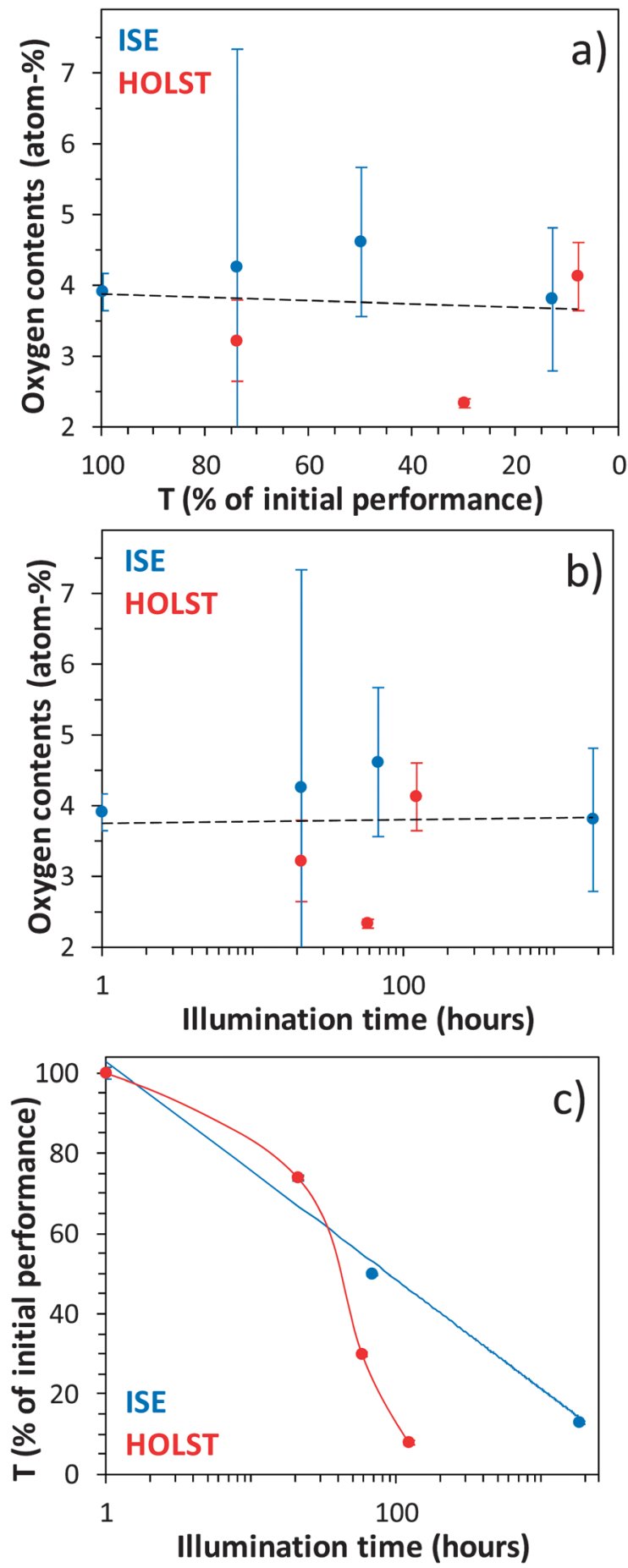

Fig. 8 (a)-(b) Oxygen contents in the bulk of the active material extracted from the TOF-SIMS depth profiling analysis of the ISE and Holst devices under full sun degradation conditions. The dashed line is a straight guide line through all points in the graph. Each point is an average of three measurements on different surface locations. The T100 Holst sample was lost. (a) Oxygen contents as a function of loss in performance. (b) Oxygen contents as a function of illumination time (AM 1.5G, $1000 \mathrm{~W} \mathrm{~m}^{-2}, 85 \pm 5^{\circ} \mathrm{C}$, metal halide lamp, KHS Solar Constant 1200 ). Zero was substituted with one on the logarithmic axis for practical purposes. (c) Loss of performance as a function of illumination time.

the Holst device under full sum simulation is caused by a thermal instability at $75^{\circ} \mathrm{C}$, which correlates well with the fact 
that under full sun conditions the temperature is $85 \pm 5{ }^{\circ} \mathrm{C}$ (AM1.5G, $1000 \mathrm{~W} \mathrm{~m}^{-2}$ ). ${ }^{15}$ Furthermore, under dark conditions the temperature corresponds to room temperature, and under fluorescent conditions the temperature is $\sim 45{ }^{\circ} \mathrm{C}$ $\left(100 \mathrm{~W} \mathrm{~m}^{-2}\right)$, which further correlates well with the fact that the performance of these particular ISE and Holst devices did not deteriorate to any significant degree during more than 1830 hours of testing. The relative temporal behaviour in performance and the significant difference in lifetimes suggest a significant difference in degradation behaviour, which is not surprising, considering the different architectures (Fig. 2a and b).

The degradation mechanisms that are in play in the ISE and Holst devices are not related to oxygen incorporation (i.e. photo-oxidation) in the active material, or at least not to any detectable degree. It should be emphasized that the interpretation is complicated by the scatter in the results. If photo-oxidation was not an important factor for the overall degradation, then other factors must have been in play for the ISE and Holst devices such as those suggested in the second and third ISOS-3 reports. ${ }^{16,17}$

In the second ISOS-3 report it was suggested that for the Holst device elevated temperatures $\left(85 \pm 5^{\circ} \mathrm{C}\right)$ caused by the sun simulator and additional heating of the cell due to current collection within the PEDOT:PSS could result in water being released from the highly conductive PEDOT:PSS, which consequently would react with the $\mathrm{Al}$ electrode, forming aluminium oxide. ${ }^{16}$ Furthermore, in the third ISOS-3 report an additional degradation mechanism was proposed for the Holst device. It was suggested that during the degradation experiment $\mathrm{Ag}$ reacts/interacts almost spontaneously with PEDOT:PSS, leading to degradation of the device performance. In addition, it was suggested that $\mathrm{Ag}$ possibly also (or alternatively) reacts with P3HT, which induces a slow but steady degradation by migration of Ag into PEDOT:PSS and oxidation of the $\mathrm{Ag}$ electrode. It was furthermore proposed that oxidation of the $\mathrm{LiF} / \mathrm{Al}$ electrode could be a possible degradation mechanism. ${ }^{17}$ Additional TOF-SIMS analyses from this work (described later in the text) on the Holst and ISE devices did not reveal any chemical changes during the degradation experiments. However, that does not necessarily mean that the degradation phenomena in question are not occurring (discussed later in the text).

With respect to the ISE device the conclusion from the second ISOS-3 report states that one possible degradation mechanism is water being homogeneously released from PEDOT:PSS that consequently reacts with $\mathrm{Cr}-\mathrm{Al}-\mathrm{Cr}$ forming chromium and aluminium oxide. ${ }^{16}$ The third ISOS-3 report has the same conclusion including possible degradation of the $\mathrm{Au}$ electrodes. ${ }^{17}$ Lira-Cantu et al. propose these degradation mechanisms based on the fact that metals like $\mathrm{Ag}, \mathrm{Cu}$, and $\mathrm{Au}$ are known to interact with the S-atom of polymers like P3HT and PEDOT, and suggests that it is thus possible that the $\mathrm{Cr} / \mathrm{P} 3 \mathrm{HT}$ :PCBM interface reacts in a similar way as well as the $\mathrm{Au} / \mathrm{PEDOT}$ :PSS interface. ${ }^{17}$

In summary, due to the impermeable encapsulation no trends were expected. However, it was not possible to detect possible subtle trends due to significant point-to-point variation for both devices. The erratic nature of the measured oxygen contents suggests that oxygen to some extent is inhomogeneously distributed in the active material, which could be the result of (i) internal oxidation caused by water originating from PEDOT:PSS or (ii) diffusion of excess PSS from PEDOT:PSS. Both of these explanations could possibly explain the elevated (on average) oxygen content compared to the calculated contents. Water release from PEDOT:PSS was suggested in the previous ISOS-3 reports. ${ }^{16,17}$ The relative performance over time suggests significantly different degradation behaviour for the two devices, which is further supported by significantly different lifetimes. Photo-oxidation was most likely not an important factor for the overall device degradation, so other factors must have been in play for the ISE and Holst devices such as for example the degradation mechanisms proposed in the second and third ISOS-3 reports. ${ }^{16,17}$

\subsubsection{UV-filter encapsulation - Risø DTU P and Risø DTU}

$\mathbf{S}$ devices. The flexible UV filter encapsulation used is to some extent permeable with respect to molecular oxygen and water (i.e. so-called semi-impermeable encapsulation), so some degree of photo-oxidation is expected. Fig. 9 displays the measured oxygen contents as a function of loss of performance and illumination time for the Risø DTU P and Risø DTU S devices. The only difference between the Risø DTU P and Risø DTU S devices is that the Risø DTU S device uses a modified version of $\mathrm{P} 3 \mathrm{HT}$ in the active material, i.e. $\mathrm{P} 3 \mathrm{HT}$-co-P3AcET instead of P3HT (see Fig. 2f for the molecular structures). The results in Fig. 9 are the most convincing, manifested in a relatively low degree of scatter.

Oxygen incorporation is observed for both devices for an increase in illumination time or for decreasing performance. The apparent linear relationship suggests that photo-oxidation could be the dominant degradation mechanism for these devices in particular. The increased level of oxygen contents in the Risø DTU S device compared to the Risø DTU P devices is due to fact that P3HT-co-P3AcET contains an ester group (Fig. 2f). Fig. 9c reveals an exponential decay in performance over time, which was also observed for the ISE device. However, this relationship does not necessarily suggest equivalent degradation mechanisms.

The two Risø DTU devices seem to have similar degradation behaviour, but there are notable differences. The slope of the Risø DTU P device in terms of oxygen incorporation is steeper than for the Risø DTU S device, which is manifested in an oxygen increase of 3.0 atom $\%$ compared to 1.8 atom $\%$ during the degradation experiments. Furthermore, the Risø DTU S device exhibited a slightly better stability as it took more than 200 hours longer to degrade, which is consistent with a lower degree of oxygen incorporation (1.8 compared to 3.0 atom $\%$ ) during testing.

The results indicate that the use of P3HT-co-P3AcET instead of P3HT induces stability. The increased stability could in principle be because P3HT-co-P3AcET has a higher resistance towards molecular oxygen and/or water, but that seems unlikely since the molecular difference is only on the side chain, i.e. not the active part of the molecule. However, the side chain affects the morphology, so it is more likely that P3HT-co-P3AcET induces a morphological stability compared to P3HT. 

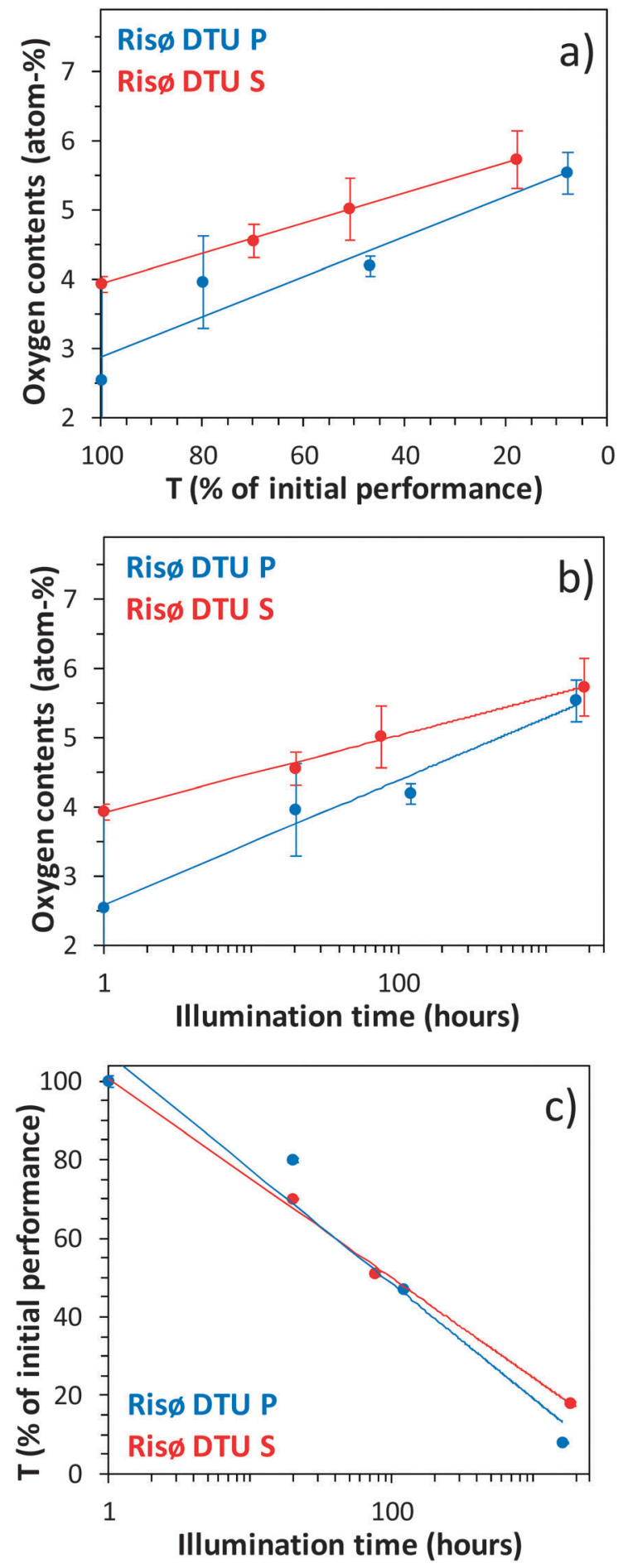

Fig. 9 (a)-(b) Oxygen contents in the bulk of the active material extracted from the TOF-SIMS depth profiling analysis of the Risø DTU $\mathrm{P}$ and Risø DTU S devices under full sun degradation conditions. Each point is an average of three measurements on different surface locations. (a) Oxygen contents as a function of loss in performance. (b) Oxygen contents as a function of illumination time (AM 1.5G, $1000 \mathrm{~W} \mathrm{~m}^{-2}$, $85 \pm 5{ }^{\circ} \mathrm{C}$, metal halide lamp, KHS Solar Constant 1200 ). Zero was substituted with one on the logarithmic axis for practical purposes. (c) Loss of performance as a function of illumination time.

In the work described in the second ISOS-3 report the population of shunts was observed to increase over time during the degradation experiments, which were suggested to be driven by electro-migration of $\mathrm{Ag}$ at places where the electric field was enhanced. ${ }^{16}$ It was furthermore proposed that oxidation of $\mathrm{Ag}$ or $\mathrm{ZnO}$ de-doping results in subtle blocking contact features. In addition, during the degradation experiments an increase in the series resistance of the devices was observed that was assigned to morphological changes/ degradation, whereas a current decrease was assigned to photo-oxidation of the active material. One notable difference was observed between the Risø DTU P and the Risø DTU S device. The latter exhibited practically no increase in series resistance, which was assigned to a more stable morphology in the active material.

In the work described in the third ISOS-3 report it was found that under dark conditions both devices are susceptible to moisture. ${ }^{17}$ However, consistent with the findings in the present work it was found that the Risø DTU S device has a higher resistance against moisture. The moisture effect was not observed under full sun or fluorescent testing conditions, i.e. where light and heat are present. This is however inconsistent with the findings in the present work, where oxygen incorporation was detected under full sun conditions only, which suggests that the moisture under dark conditions is involved in degradation mechanisms other than photooxidation of the active material. This is consistent with the proposed mechanisms in the third ISOS-3 report that include oxidation of the $\mathrm{Ag}$ electrode and migration of $\mathrm{Ag}$ provoked by PEDOT due to well-documented Ag-S interactions. ${ }^{17}$ It was proposed that the higher stability of the Risø DTU S device is caused by an impeding effect of having used P3HTco-P3AcET in the reaction with Ag, which will inhibit degradation of the electrodes. Finally, it was suggested that it is the degradation of the electrodes that initially is responsible for the overall degradation of performance and not degradation of the active materials.

In summary, because a so-called semi-impermeable encapsulation was used some degree of photo-oxidation was expected for the Risø DTU P and Risø DTU S devices, which was indeed also observed. An apparent linear relationship is observed for oxygen incorporation as a function of loss in performance and an exponential increase of oxygen incorporation as a function of time, suggesting that photo-oxidation could be the dominant degradation mechanism. Using P3HT-co-P3AcET instead of P3HT induces stability, which is most likely morphological stability causing less oxygen to be incorporated resulting in a longer lifetime. Conclusions on the relative stability are supported by the findings in the previous ISOS-3 reports. ${ }^{16,17}$

3.2.5 No encapsulation - NREL and IMEC devices. The NREL and IMEC devices have no encapsulation and are thus expected to be significantly photo-oxidated during full sun testing conditions. The device architectures (Fig. 2d and e) are very similar, the only significant difference is the hole transport layer that consists of PEDOT:PSS (NREL device) or $\mathrm{MoO}_{3}$ (IMEC device). Any observed differences in degradation behaviour should therefore be directly related to the difference in the hole transport layer used.

Fig. 10 displays the measured oxygen contents as a function of loss of performance and illumination time for the NREL 

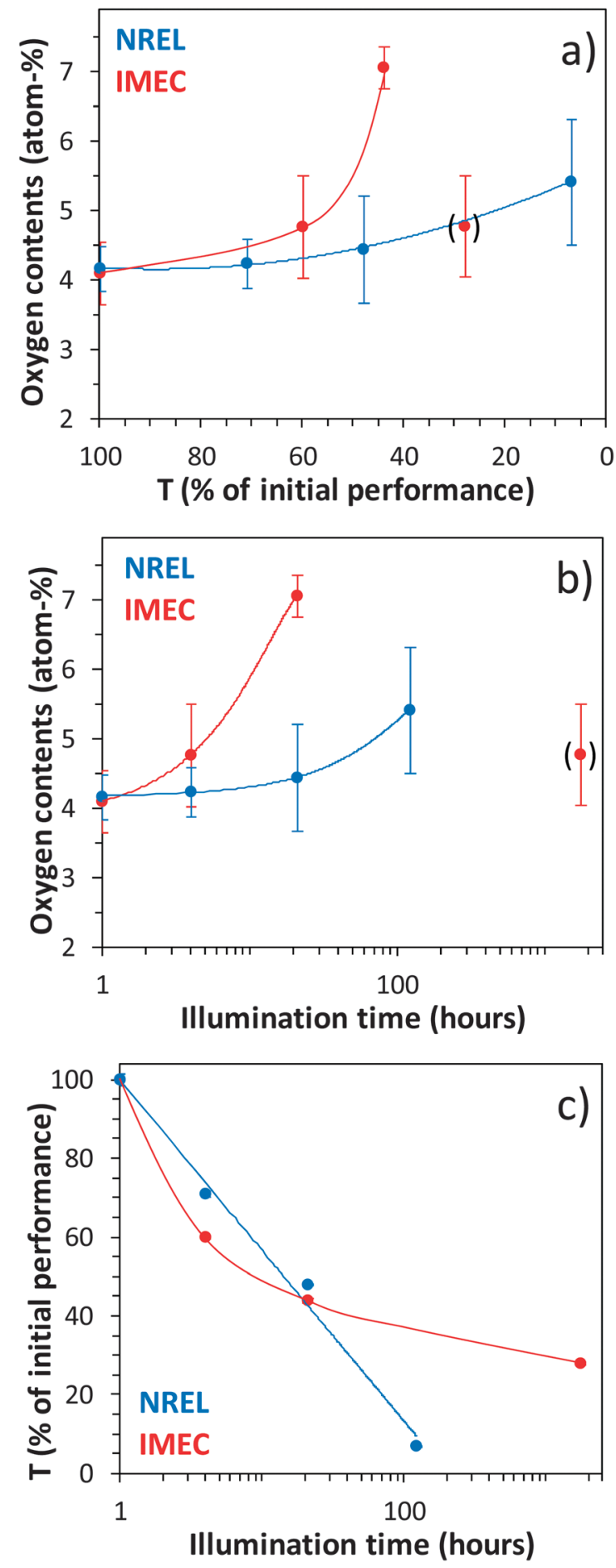

Fig. 10 (a)-(b) Oxygen contents in the bulk of the active material extracted from the TOF-SIMS depth profiling analysis of the NREL and IMEC devices under full sun degradation conditions. Each point is an average of three measurements on different surface locations. (a) Oxygen contents as a function of loss in performance. (b) Oxygen contents as a function of illumination time (AM 1.5G, $1000 \mathrm{~W} \mathrm{~m}^{-2}$, $85 \pm 5{ }^{\circ} \mathrm{C}$, metal halide lamp, KHS Solar Constant 1200). Zero was substituted with one on the logarithmic axis for practical purposes. (c) Loss of performance as a function of illumination time.

and IMEC devices. The oxygen incorporation is observed as expected to increase for a decrease in performance or increase in illumination time (Fig. 10a and b). The T28 IMEC sample was erroneous, which was documented from a comparison of the IV degradation characteristics that showed a clear inconsistency for the T28 IMEC sample that consequently was omitted.

Considering that these devices had no encapsulation during the full sun illumination it is surprising that such a small amount of oxygen was incorporated. The oxygen content increased by 1.3 atom $\%$ for the NREL device and by 3.0 atom $\%$ for the IMEC device, the latter being equivalent to the Risø DTU P device that had a so-called semi-impermeable encapsulation. Both devices start out with a slow oxygen incorporation that later on accelerates, which is a completely different situation compared to the Risø DTU devices that exhibited a linear increase.

Fig. 10c shows an exponential decay in performance over time for the NREL device, which was also observed for the ISE and Risø DTU devices. The NREL device reaches T7 within 122 hours, which is relatively fast and equivalent to the Holst device. However, in terms of performance loss over time the Holst device (Fig. 8c) has a significantly different behaviour, suggesting that different degradation mechanisms are in play. The performance loss over time for the IMEC device (Fig. 10c) is interesting since the behaviour is the opposite compared to the Holst device. Initially the performance for the IMEC device drastically decreases but levels out and stabilizes and surprisingly (since no encapsulation is used) ends up having a long lifetime (reaches T28 after 1751 hours). The IMEC device is the fastest to incorporate oxygen in the active material, but has a lifetime comparable with the encapsulated devices (except for the Holst device). It is tempting to assign the significantly different degradation behaviour of the IMEC device compared to the NREL device to the different hole transport layer $\left(\mathrm{MoO}_{3}\right.$ instead of PEDOT:PSS). However, another difference is the $200 \mathrm{~nm}$ thick $\mathrm{Al}$ electrode on the IMEC device compared to only $100 \mathrm{~nm}$ on the NREL device, which must be significant in terms of the barrier properties. Having said that, the $\mathrm{MoO}_{3}$ layer must also have different barrier properties than PEDOT:PSS. $\mathrm{MoO}_{3}$ is well-known to induce better stability towards ambient atmosphere compared to PEDOT:PSS. ${ }^{23}$ One thing is clear, the IMEC device has a complex degradation behaviour that calls for complementary analysis results.

The second ISOS-3 report offers a lot of discussion on possible degradation mechanisms in the IMEC device. ${ }^{16}$ The degradation mechanisms are described as initially being two competing processes involving $\mathrm{Ag}$ penetration into $\mathrm{MoO}_{3}$ and oxidation of Ag. The acting work function in direct vicinity to active layer becomes reduced at the place where Ag penetration is occurring. Later on blocking contact features start to occur. It was suggested that diffusion of molecular oxygen and/or water into the device could result in increasing barriers for charge injection and extraction by formation of $\mathrm{Ag}_{2} \mathrm{O}$ or by dedoping at the $\mathrm{ZnO}$ layer.

The degradation behaviour of the NREL device is also described in the second ISOS-3 report. ${ }^{16}$ It was found that a massive degree of shunting developed over large parts of the NREL device mainly at the places where injection remained possible after oxidation of $\mathrm{Ag}$, i.e. around pinholes and at the 
edges of the metal electrode. It was concluded that electromigration of $\mathrm{Ag}$ resulted in penetration of the PEDOT:PSS layer, which was proposed to be significantly less dense than the $\mathrm{MoO}_{3}$ layer. ${ }^{23}$

The third ISOS-3 report describes significant problems in characterizing the NREL device using IPCE. ${ }^{17}$ It was not possible to detect possible trends due to an erratic response from the IPCE analysis. The erratic response was believed to be caused by a reversible uptake of water in the hygroscopic PEDOT:PSS that highly depended on the relative humidity at the time and place of analysis. It was nevertheless possible to detect an interaction between $\mathrm{Ag}$ and the sulphur in PEDOT:PSS, which together with the water uptake was taken as an indication that degradation takes place at the electrodes consequently reducing the flux of current throughout the cell over time. The combined degradation phenomenon affected the cells inhomogeneously, which was manifested in a significant variation in the IPCE results within the same cell on the device/substrate and between different cells on the same device/ substrate. The erratic response was also observed in the present work for the NREL device (large error bars in Fig. 10a and b), but that is not necessarily the same phenomenon since the erratic response is also observed for the impermeable encapsulated devices (Fig. 8a and b) in the present work.

In an in situ IPCE analysis on the NREL device the charge transfer complex was identified and it was possible to monitor the release of molecular oxygen over time. The reversible formation of the charge transfer complex will unavoidably contribute to the erratic response when analyzing devices without encapsulation. As described earlier in the text this phenomenon was not significant in the present work. From the in situ IPCE analysis it was furthermore possible to monitor release of oxygen from the $\mathrm{ZnO}$ crystalline structure. Finally, The IPCE analyses supported the findings from the second ISOS- 3 report that electro-migration of Ag into the PEDOT:PSS layer occurs. ${ }^{16}$

A lot of the features found in the NREL device were also found in the IMEC device including the charge transfer complex. However, one important observation was a significantly smaller degree of erratic response in the IMEC device that supported the conclusion that PEDOT:PSS was a significant contributor to the erratic response. However, at longer times in the degradation experiment a non-uniform effect of the cell position on the device/substrate started to emerge. By comparing the IPCE results from an encapsulated IMEC device and one without encapsulation it was concluded that the ambient atmosphere is modifying the properties of $\mathrm{MoO}_{3}$ and $\mathrm{ZnO}$. When the IPCE analysis was performed in a nitrogen atmosphere on the IMEC and NREL devices, oxygen was observed to release from $\mathrm{MoO}_{3}$ and $\mathrm{ZnO}$, which is a wellknown phenomenon for semiconductor oxides. The oxygen release from $\mathrm{MoO}_{3}$ and $\mathrm{ZnO}$ will change the properties of the materials (including the photovoltaic properties) and provide a source of oxygen that can react with the organic materials such as the active layer (i.e. internal oxidation).

In summary, without encapsulation the NREL and IMEC devices were expected to be significantly photo-oxidated during full sun testing conditions, but surprisingly the level of photo-oxidation in the active material corresponded to the semi-encapsulated devices. A slow oxygen incorporation is observed initially that accelerates at longer times. The IMEC device has a surprisingly long lifetime compared to the NREL device, which is attributed to the only significant difference between the devices, which is the hole transport layer that consisted of PEDOT:PSS (NREL) and $\mathrm{MoO}_{3}$ (IMEC). $\mathrm{MoO}_{3}$ is well-known to induce better stability compared to PEDOT:PSS towards ambient atmosphere. ${ }^{23}$

\subsection{Correlating LBIC and TOF-SIMS data}

LBIC visualizes the relative light-beam induced current typically over the entire solar cell area, which is useful for pinpointing where the current is low or zero in the lateral plane of the cell. However, the LBIC analysis contains no in-depth information that would otherwise reveal in which layer or interface the phenomenon causing the loss of current is located. In the second ISOS-3 report LBIC was employed and correlated with related techniques such as photoluminescence imaging (PLI), electroluminescence imaging (ELI), and lock-in thermography (LIT) that each provides useful complementary in-plane information based on different sensing characteristics. ${ }^{16}$ The strength of this approach lies in the multitude of techniques (i.e. sensing characteristics) used to conclude on specific degradation mechanisms, which compensates for the indirect nature of the information (i.e. lack of in-depth information).

In this work an attempt was made to correlate LBIC data with TOF-SIMS data. TOF-SIMS provides three-dimensional chemical information, i.e. direct chemical information in-plane as well as in-depth. However, this comparison is not necessarily straightforward since the LBIC detected cell degradation could be caused by a missing contact, i.e. not a chemical phenomenon. Furthermore, if the degradation is caused by an interface phenomenon (often the case) the limited depth resolution of the in-depth analysis could be an issue. Diffusion of water and molecular oxygen into the device resulting in photo-oxidation is a degradation mechanism that has been described thoroughly in the past and is the focus of this present work..$^{18,24-30} \mathrm{An}$ available glass-encapsulated IMEC device was therefore chosen for the comparison, which should exclude this specific welldescribed degradation mechanism.

The grey images in Fig. 11 represent the LBIC images for the IMEC device in question (see Fig. 2e for cell configuration). The device consists of 12 cells of which cells 1-3 were defective and 7 and 8 were apparently interconnected (equivalent LBIC images). After the LBIC analysis the device was transferred to a glove box where the glass encapsulation was removed. An attempt was made to peel off the $\mathrm{Al}-\mathrm{Ag}-\mathrm{MoO}_{3}$ stack of the cells in order to access the $\mathrm{MoO}_{3} / \mathrm{P} 3 \mathrm{HT}$ :PCBM interface. It is usually very easy to peel off the upper electrode on pristine cells, but illuminated/heated cells typically either do not peel off or only partly peel off depending on the cell configuration and the degree of illumination/heating. It is thus interesting that the peel off process was almost complete for the defective cells (1-3). The partially delaminated cells (4-12) were then transferred in an inert atmosphere to the TOFSIMS instrument. A TOF-SIMS imaging analysis was performed on cells 4-12. 


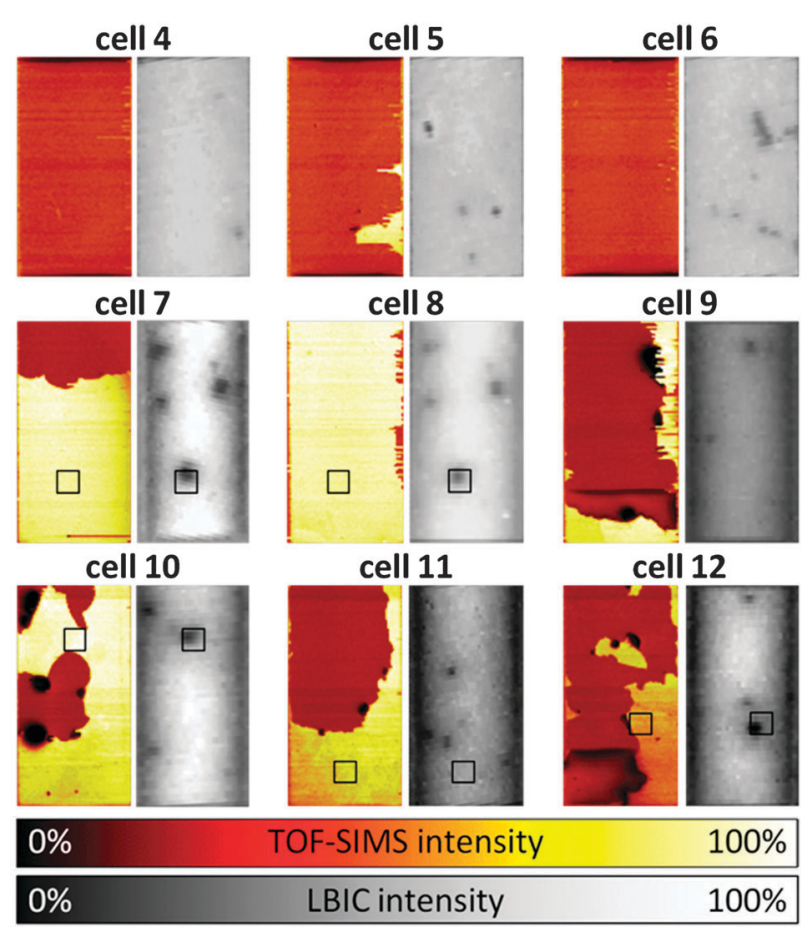

Fig. 11 Analytical results of cells 4-12 (1-3 were defective) from an encapsulated IMEC device. The grayscale images are LBIC images and the color images are the corresponding TOF-SIMS total ion images $\left(5.2 \times 2.7 \mathrm{~mm}^{2}\right)$. The squares indicate areas $\left(500 \times 500 \mu \mathrm{m}^{2}\right)$ that were analyzed with TOF-SIMS depth profiling. The $\mathrm{Al}-\mathrm{Ag}-\mathrm{MoO}_{3}$ layers were partly removed prior to TOF-SIMS analysis (the yellow/ white areas correspond to the $\mathrm{Al}$ surface).

The coloured images in Fig. 11 represent the total ion images of the cell surfaces. The high intensity areas (yellow/ white) correspond to the Al surface and the dark red areas correspond to the exposed P3HT:PCBM surface (i.e. $\mathrm{MoO}_{3} /$ P3HT:PCBM interface). The total ion signal is a convenient way to screen for chemical contrast on the surface. As is evident from Fig. 11 there are no correlations between the LBIC images and the TOF-SIMS total ion images. The TOFSIMS images are actually extremely homogeneous. The dark spots are instrument effects caused by flakes of upwardbended $\mathrm{Al}-\mathrm{Ag}-\mathrm{MoO}_{3}$ causing loss of signal. It can now be concluded that localized loss of current in the cells (black spots in the LBIC images) is not related to a chemical phenomenon at the $\mathrm{MoO}_{3} / \mathrm{P} 3 \mathrm{HT}$ :PCBM interface. However, it is not possible to conclude anything about a possible missing contact between $\mathrm{MoO}_{3}$ and P3HT:PCBM from the TOF-SIMS ion images in Fig. 11.

The next step was to study the remaining layers and interfaces in the cells. TOF-SIMS depth profiling was performed on surface locations indicated by the squares in Fig. 11. In a TOF-SIMS depth profiling analysis ion images are acquired as a function of depth. Ion images from 100 of the most abundant mass spectral markers were monitored as a function of depth in order to find a possible correlation between the LBIC image and the TOF-SIMS ion images. The depth profiling analyses were started at surface locations that partly covered (to get chemical contrast) the dark spots in the corresponding LBIC images with one exception (cell 11, reference location).
All ion images were monitored through all layers and interfaces, i.e. from the $\mathrm{Al}$ surface to the bulk of the ITO. Unfortunately all ion images were extremely homogenous in all depths, which means that the degradation mechanism in question was not detectable by TOF-SIMS depth profiling.

\subsection{Correlating loss of performance with various TOF-SIMS information}

The primary objective of the TOF-SIMS investigation of the ISOS-devices was to correlate the photo-oxidation of the active layer with loss of cell performance. However, as documented in the previous ISOS- 3 reports, photo-oxidation of the active material is not the only degradation mechanism in play during operation of the organic solar cells. ${ }^{16,17}$ The different cell architectures enable a variety of degradation mechanisms to contribute to the overall degradation of the cell. When the TOF-SIMS depth profiling analyses were performed relevant information was extracted from the raw data so that the photo-oxidation could be adequately described. The raw data consist of mass spectral data, which contain an overwhelming amount of information. This is one of the reasons that the TOF-SIMS technique is so attractive, but it is also the reason why it is often very complicated to interpret the results. It is tremendously less complicated if one knows what to look for. However, it should be emphasized that it is not possible to detect all degradation mechanisms. The raw data consist of mass spectral information, and mass spectral markers are typically chosen to represent a species that somehow is involved in the degradation mechanism or to support conclusions made on other mass spectral markers. The problem is that not all mass spectral markers are unique. One good example of a situation where it was not possible to extract direct information is the proposed mechanism involving migration of water from the PEDOT:PSS. Water produces mass spectral markers that are the same for all species containing oxygen, i.e. no unique markers. It is possible to detect the resulting oxidation, i.e. indirect information that requires assumption to be made. It is not impossible to study migration of water out of PEDOT:PSS, however, that would require a specially designed experiment where isotopically labelled water is used $\left(\mathrm{H}_{2}{ }^{18} \mathrm{O}\right)$, which produces unique mass spectral markers. It has previously been shown that $\mathrm{H}_{2}{ }^{18} \mathrm{O}$ is easily tracked in OPV devices from its reaction/degradation products. ${ }^{25}$

The secondary goal of this study was to carefully study the raw data in detail in order to ascertain whether trends related to loss of performance could be extracted and possibly related to specific degradation mechanisms such as those suggested in the previous ISOS-3 reports. ${ }^{16,17}$ This was partially achieved and the result is presented and discussed in the following.

3.4.1 The IMEC device. The IMEC device is by far the most complex system to analyze in terms of degradation mechanisms. The cell configuration is $\mathrm{Al}-\mathrm{Ag}-\mathrm{MoO}_{3}-$ P3HT:PCBM-ZnO-ITO and mass spectral information is obtained throughout the entire device starting from the outer aluminium surface and ending somewhere in the bulk of the ITO layer. Due to the poor depth resolution that gets worse for longer sputter times it is difficult to extract certain types of information from deeper layers, e.g. interface phenomena 


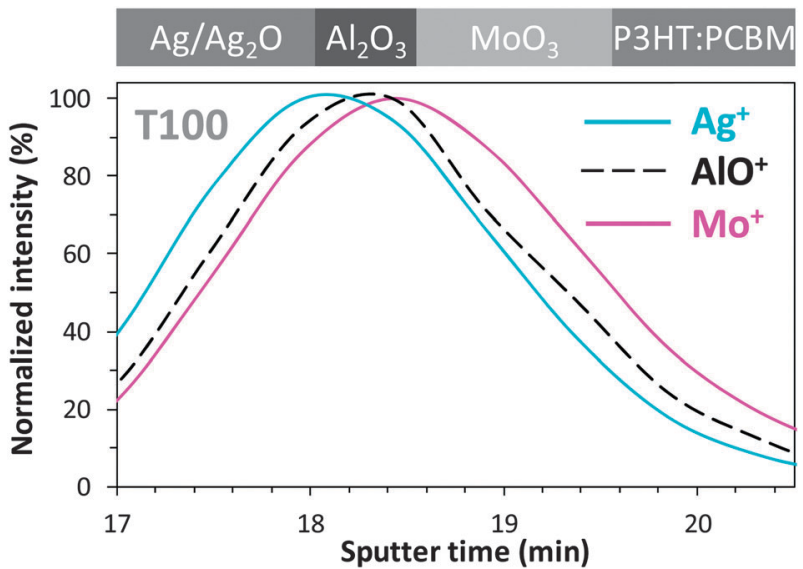

Fig. 12 TOF-SIMS depth profiles for a T100 IMEC cell that was exposed to full sun conditions without encapsulation. The sputter time window is chosen to emphasize the existence of a thin $\mathrm{Al}_{2} \mathrm{O}_{3}$ layer at the $\mathrm{Ag} / \mathrm{MoO}_{3}$ interface, which is present in all the IMEC devices. The indicated ions are mass spectral markers chosen to represent the individual layers. The schematic on top of the plot illustrates the part of the layer stack the data were extracted from.

occurring at P3HT:PCBM/ZnO and $\mathrm{ZnO} / \mathrm{ITO}$ that produces weak possible generic mass spectral markers. Since the active layer was thoroughly investigated in the primary work described herein, it made sense to focus on the upper layers $\left(\mathrm{Al}-\mathrm{Ag}-\mathrm{MoO}_{3}\right)$.

Upon close inspection of the raw data from the upper layers one surprising observation was made, which is presented in Fig. 12. A layer of $\mathrm{Al}_{2} \mathrm{O}_{3}$ is present at the $\mathrm{Ag} / \mathrm{MoO}_{3}$ interface. Fig. 12 shows a narrow sputter time window around that interface. The dashed line representing $\mathrm{Al}_{2} \mathrm{O}_{3}$ is located exactly between the $\mathrm{Ag}$ and $\mathrm{MoO}_{3}$ layers and is presumably very thin. The reason that the $\mathrm{MoO}_{3}$ layer $(10 \mathrm{~nm})$ appears so thick compared to the $\mathrm{Ag}$ layer $(100 \mathrm{~nm})$ is the poor depth resolution and a large detector response from $\mathrm{MoO}_{3}$. This is a more plausible explanation rather than possible differences in sputter rates. The profiles in Fig. 12 are extracted from a T100 device, so the phenomenon must have occurred during fabrication or in the time between fabrication and analysis. The $\mathrm{Al}_{2} \mathrm{O}_{3}$ at the $\mathrm{Ag} / \mathrm{MoO}_{3}$ interface could be the result of aluminium migration from the $\mathrm{Al}$ electrode through the $\mathrm{Ag}$ layer and subsequent oxidation somehow. Alternatively, it could be $\mathrm{Al}_{2} \mathrm{O}_{3}$ migration from $\mathrm{MoO}_{3}$ that (like $\mathrm{ZnO}$ ) contains trace amounts of various metal oxides. $\mathrm{Al}_{2} \mathrm{O}_{3}$ is not observed at the $\mathrm{MoO}_{3} / \mathrm{P} 3 \mathrm{HT}$ :PCBM interface, so if the latter explanation is correct the phenomenon must be catalyzed by the adjacent Ag layer.

Fig. 13 displays the profiles for the mass spectral marker $\mathrm{AlO}^{-}$representing $\mathrm{Al}_{2} \mathrm{O}_{3}$ over a sputter time window covering $\mathrm{Al}-\mathrm{Ag}-\mathrm{MoO}_{3}$. As is evident from Fig. $13 \mathrm{Al}_{2} \mathrm{O}_{3}$ is present in the $\mathrm{T} 100$ cell through the entire $\mathrm{Al}$ electrode and is accumulated at the air/ $\mathrm{Al}$ interface and at the $\mathrm{Al} / \mathrm{Ag}$ interface (and in the unintentional $\mathrm{Al}_{2} \mathrm{O}_{3}$ layer). The intensity of $\mathrm{AlO}^{-}$clearly increases for decreasing cell performance consistent with $\mathrm{Al}_{2} \mathrm{O}_{3}$ formation as a result of molecular oxygen and water diffusing into the cell (i.e. no encapsulation) that consequently reacts with $\mathrm{Al}$. This is one of the proposed degradation mechanisms presented in the second and third ISOS-3 reports. ${ }^{16,17}$ It should be noted that one other phenomenon can affect the

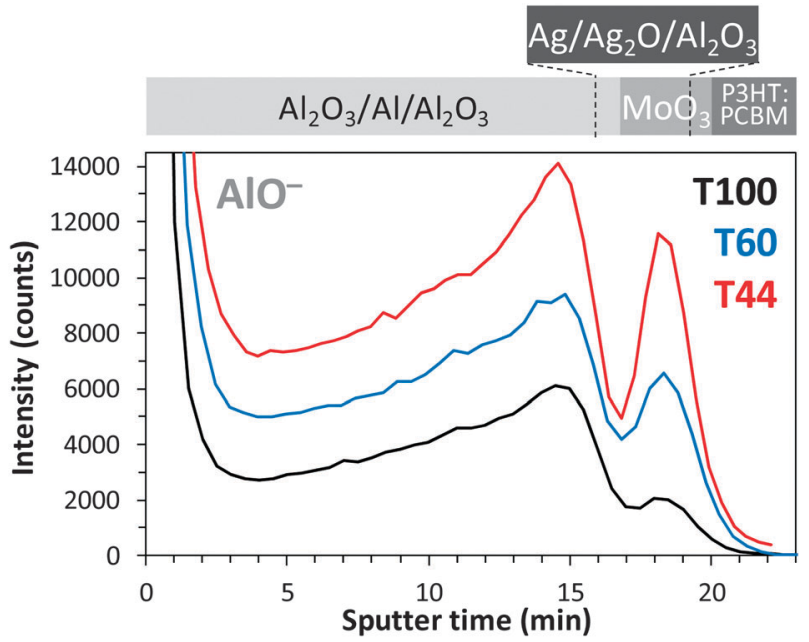

Fig. 13 TOF-SIMS depth profiles for IMEC cells exposed to full sun conditions without encapsulation. The profiles show a massive build-up of aluminum oxide in the $\mathrm{Al}-\mathrm{Ag}-\mathrm{MoO}_{3}$ region of the cells for decreasing cell performance. $\mathrm{AlO}^{-}$is the mass spectral marker chosen to represent aluminum oxide. The schematic on top of the plot illustrates the part of the layer stack the data were extracted from.

intensity of a mass spectral marker. If the physical properties of the material change it could affect the detector response, e.g. crystallinity, electric conductivity, etc. However, these possible effects are small compared to the intense signal boost you get for an increase in $\mathrm{Al}_{2} \mathrm{O}_{3}$ concentration.

The clear correlation between accumulation of $\mathrm{Al}_{2} \mathrm{O}_{3}$ and loss of cell performance suggests that this phenomenon is at least partly responsible for the degradation of the photovoltaic response. Unfortunately it is not possible to quantify how much this degradation mechanism is contributing to the overall degradation of the photovoltaic response. Furthermore, it is not possible to determine how much the $\mathrm{Al}_{2} \mathrm{O}_{3}$ at the $\mathrm{Ag} / \mathrm{MoO}_{3}$ interface contributes compared to the $\mathrm{Al}_{2} \mathrm{O}_{3}$ at the $\mathrm{Al} / \mathrm{Ag}$ interface, but it is possible to conclude that $\mathrm{Al}_{2} \mathrm{O}_{3}$ accumulation at the $\mathrm{Ag} / \mathrm{MoO}_{3}$ interface is faster than at the $\mathrm{Al} / \mathrm{Ag}$ interface.

The comparison between LBIC images and TOF-SIMS data involved an encapsulated IMEC device. The availability of an encapsulated IMEC device makes it obvious to compare the TOF-SIMS depth profiling data with and without encapsulation. Fig. 14 sums the results of that comparison. The T44 device without encapsulation was illuminated in ambient air for 21 hours, and the T50 device with encapsulation (glass) was illuminated for 2600 hours, which demonstrates the strength of glass encapsulation.

The first interesting observation is the lack of $\mathrm{Al}_{2} \mathrm{O}_{3}$ at the $\mathrm{Al} / \mathrm{Ag}$ interface for the device with encapsulation. Half way through the $\mathrm{Al}$ electrode the $\mathrm{AlO}$ profiles are practically the same, but then the concentration of $\mathrm{Al}_{2} \mathrm{O}_{3}$ decreases to zero. Unfortunately it was not possible to obtain a T100 device with encapsulation, which would have been an interesting comparison. It appears that the encapsulated device was fabricated with no $\mathrm{Al}_{2} \mathrm{O}_{3}$ at all at the $\mathrm{Al} / \mathrm{Ag}$ interface, which is impressive from a technical point of view.

The second interesting observation is the intensity of the $\mathrm{Al}_{2} \mathrm{O}_{3}$ at the $\mathrm{Ag} / \mathrm{MoO}_{3}$ interface, which is significantly elevated 


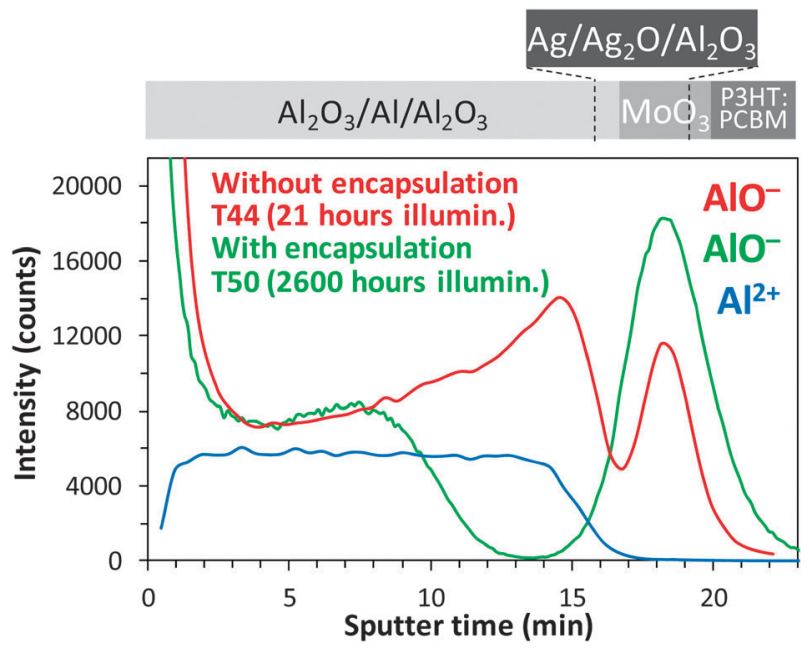

Fig. 14 TOF-SIMS depth profiles for IMEC cells exposed to full sun conditions with and without encapsulation (glass). The device without encapsulation was illuminated for 21 hours (T44), and the encapsulated device was illuminated for 2600 hours (T50). The profiles show the relative build-up of aluminium oxide in the $\mathrm{Al}-\mathrm{Ag}-\mathrm{MoO}_{3}$ region of the cells. $\mathrm{AlO}^{-}$is the mass spectral marker chosen to represent aluminium oxide. The $\mathrm{Al}^{2+}$ profile (T100 device without encapsulation) was included to define the exact sputter time window for the $\mathrm{Al}$ electrode. Different sputter properties were used for the encapsulated device, so the sputter time was corrected such that the $\mathrm{AlO}^{-}$ peak at the $\mathrm{Ag} / \mathrm{MoO}_{3}$ interface was aligned. The schematic on top of the plot illustrates the part of the layer stack the data were extracted from.

for the encapsulated device compared to the device without encapsulation. This is somewhat difficult to speculate on considering the lack of ambient air for the encapsulated device. It is still possible that $\mathrm{Al}_{2} \mathrm{O}_{3}$ originates from migration from the $\mathrm{MoO}_{3}$ layer (as an impurity). A more farfetched explanation could be that $\mathrm{Al}_{2} \mathrm{O}_{3}$ migrates from the $\mathrm{Al} / \mathrm{Ag}$ interface, which could explain why no $\mathrm{Al}_{2} \mathrm{O}_{3}$ is present at the $\mathrm{Al} / \mathrm{Ag}$ interface (i.e. depletion). Since the encapsulated device has only reached T50 after 2600 hours it would seem that the presence of $\mathrm{Al}_{2} \mathrm{O}_{3}$ at the $\mathrm{Ag} / \mathrm{MoO}_{3}$ interface is not deteriorating the photovoltaic performance, which is surprising. The $\mathrm{Al}^{2+}$ profile (T100 device without encapsulation) was included in Fig. 14 to define the exact sputter time window for the Al electrode. The shape of the $\mathrm{Al}^{2+}$ profile did not change as a function of loss of cell performance.

The encapsulated IMEC device revealed another difference when compared to the corresponding device without encapsulation (Fig. 15). The mass spectral marker $\mathrm{OH}^{-}$is typically formed (during the ionization part of the analysis) in metal oxides with limited intensity compared to $\mathrm{O}^{-}$. However, on metal oxide surfaces exposed to an atmosphere the $\mathrm{M}-\mathrm{OH}$ groups will typically be abundant resulting in a very intense $\mathrm{OH}^{-}$signal intensity. The mass spectral marker $\mathrm{OH}^{-}$is detected at the $\mathrm{Ag} / \mathrm{MoO}_{3}$ interface (Fig. 15) for both devices, which is not as interesting as the fact that it is also detected at the $\mathrm{Al}_{2} \mathrm{O}_{3} / \mathrm{Ag}$ interface, but only for the encapsulated device. The $\mathrm{OH}^{-}$profile for the encapsulated device appears to be wider than the corresponding profiles for the device without encapsulation, which could be due to the fact that other

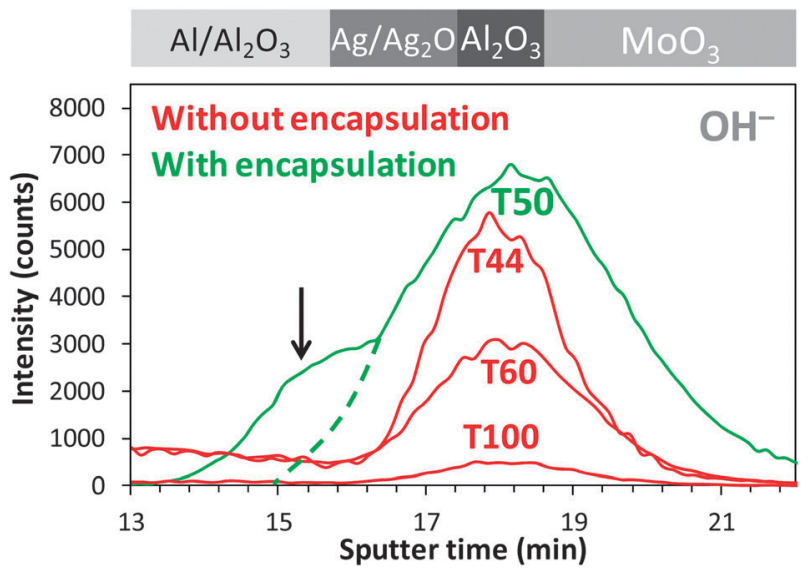

Fig. 15 TOF-SIMS depth profiles for IMEC cells exposed to full sun conditions with (green) and without (red) encapsulation (glass). The device without encapsulation was illuminated for 21 hours (T44), and the encapsulated device was illuminated for 2600 hours (T50). The intensity of the mass spectral marker $\mathrm{OH}^{-}$increases (like $\mathrm{AlO}^{-}$and $\mathrm{O}^{-}$) in the unintentional aluminum oxide layer for decreasing cell performance. An additional $\mathrm{OH}^{-}$peak indicated by the arrow is observed for the device without encapsulation at the $\mathrm{Al}_{2} \mathrm{O}_{3} / \mathrm{Ag}$ interface. The dashed line is drawn to clarify that the additional $\mathrm{OH}^{-}$ profile peak (arrow) for the encapsulated device overlaps with the other $\mathrm{OH}^{-}$profile peak and takes the form of a "shoulder". Different sputter properties were used for the encapsulated device, so the sputter time was corrected such that the $\mathrm{AlO}^{-}$peak at the $\mathrm{Ag} / \mathrm{MoO}_{3}$ interface was aligned. The schematic on top of the plot illustrates the part of the layer stack the data were extracted from.

sputter properties were used for the encapsulated device (the sputter time axis was corrected to allow comparison). It is difficult to speculate on what type of chemistry would explain the additional $\mathrm{OH}^{-}$signal (arrow in Fig. 15) at the $\mathrm{Al}_{2} \mathrm{O}_{3} / \mathrm{Ag}$ interface. Since the phenomenon is observed on the stable device (T50 after 2600 hours) it is unlikely that it is related to degradation of the photovoltaic performance.

In the second and third ISOS-3 reports silver migration and silver oxidation were suggested to be involved in degradation mechanisms. ${ }^{16,17}$ The mass spectral marker $\mathrm{AgO}^{-}$representing silver oxide was detected on all the IMEC devices at the $\mathrm{Ag} / \mathrm{Al}_{2} \mathrm{O}_{3}$ interface (Fig. 16). As is evident from Fig. 16 the $\mathrm{AgO}^{-}$intensity is observed to increase for decreasing cell performance. However, it should be noted that the intensity is extremely weak (barely detectable). The apparent trace amount of $\mathrm{Ag}_{2} \mathrm{O}$ is observed starting from all surface locations. It was not possible to detect silver migration. However, it should be emphasized that the TOF-SIMS depth profiling analyses are performed on random surface locations, i.e. not necessarily at lateral surface positions where degradation is more pronounced as described in the second ISOS-3 report where various imaging techniques were employed to visualize the lateral degradation patterns. ${ }^{16}$

3.4.2 The NREL device. The NREL device has the architecture Al-Ag-PEDOT:PSS-P3HT:PCBM-ZnO-ITO. As mentioned earlier in the text, the device differs only by the hole transport layer compared to the IMEC device, i.e. PEDOT:PSS instead of $\mathrm{MoO}_{3}$. At first one would thus expect the degradation 


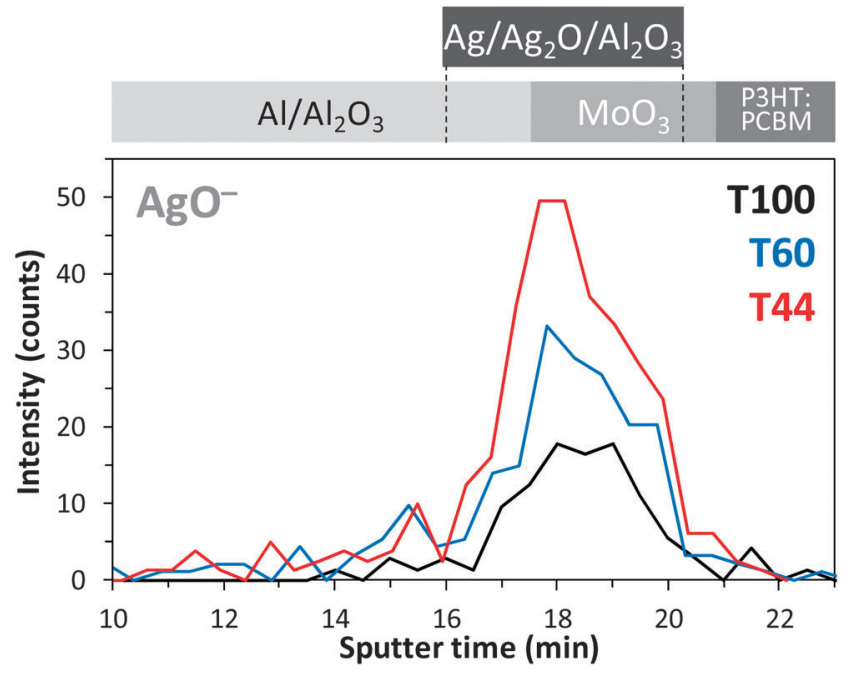

Fig. 16 TOF-SIMS depth profiles for IMEC cells exposed to full sun conditions. The profiles show a very subtle increase in the intensity of the mass spectral marker $\mathrm{AgO}^{-}$for decreasing cell performance, which most likely corresponds to a small degree of silver oxide formation. The schematic on top of the plot illustrates the part of the layer stack the data were extracted from.

mechanisms to be similar. It turns out that besides similarities there are also surprising differences.

The first observation is the same as that for the IMEC device (with no encapsulation), that $\mathrm{Al}_{2} \mathrm{O}_{3}$ is observed to accumulate for decreasing cell performance (not shown), which was expected based on the fact that no encapsulation was employed. Formation of $\mathrm{Al}_{2} \mathrm{O}_{3}$ is consistent with conclusions drawn in the previous ISOS-3 reports. ${ }^{16,17}$ The second observation is the lack of the additional (unintentional) $\mathrm{Al}_{2} \mathrm{O}_{3}$ layer (see Fig. 12), which suggests that its existence in the IMEC device is related to $\mathrm{MoO}_{3}$ one way or the other.

Fig. 17 reveals another interesting phenomenon not observed in the IMEC device. The profiles representing the $\mathrm{Ag}, \mathrm{Al}_{2} \mathrm{O}_{3}$, and PEDOT:PSS layers are observed to systematically widen for decreasing cell performance. In addition, $\mathrm{Al}_{2} \mathrm{O}_{3}$ and $\mathrm{Ag}$ have exactly the same sputter times (not shown), so it looks like the $\mathrm{Al}_{2} \mathrm{O}_{3}$ from the $\mathrm{Al} / \mathrm{Ag}$ interface is dissolving in the $\mathrm{Ag}$ layer that consequently thickens the Ag layer (Fig. 17a). When $\mathrm{Al}_{2} \mathrm{O}_{3}$ expands into the Ag layer the result will be a widening of the $\mathrm{AlO}^{-}$profile as shown in Fig. 17b.

The $\mathrm{Al}^{2+} \mathrm{T} 100$ profile shown Fig. $17 \mathrm{~d}$ is consistent with the IMEC device, i.e. the expected depth profile for a normal Al electrode. However, unlike the IMEC device, this profile changes drastically for decreasing cell performance. The $\mathrm{Al}^{2+}$ signal is systematically lost at the $\mathrm{Al} / \mathrm{Ag}$ interface for decreasing cell performance. This supports the proposed phenomenon of $\mathrm{Al}_{2} \mathrm{O}_{3}$ and apparently also $\mathrm{Al}$ dissolving in the $\mathrm{Ag}$ layer. This is not observed for the IMEC device, suggesting that PEDOT:PSS is involved in the phenomenon, possibly from migration of water or acid from PEDOT:PSS to the $\mathrm{Al} / \mathrm{Ag}$ interface.

Fig. 17c displays the $\mathrm{Na}^{+}$profiles that also widen for decreasing cell performance. $\mathrm{Na}^{+}$is a native component in PEDOT:PSS and is thus representative for PEDOT:PSS. The same trend is observed for the $\mathrm{SO}_{x}{ }^{-}$profiles, which are also representative of PEDOT:PSS (less pronounced trend though, not shown). The $\mathrm{Na}^{+}$profile is not just widening but also shifting to higher sputter times, suggesting that PEDOT:PSS is

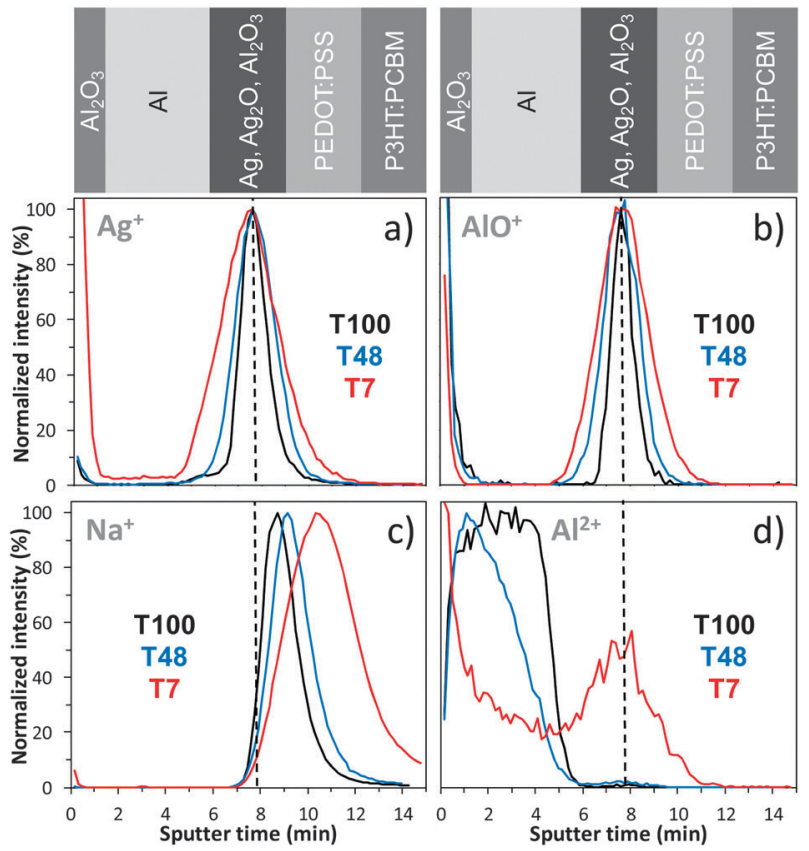

Fig. 17 (a)-(d) TOF-SIMS depth profiles for NREL cells exposed to full sun conditions. (a)-(c) The profiles of the mass spectral markers $\mathrm{Ag}^{+}, \mathrm{AlO}^{+}, \mathrm{Na}^{+}$exhibit a widening in the sputter time window for decreasing cell performance. (b) The $\mathrm{AlO}^{+}$intensities increase (not shown) for decreasing cell performance, i.e. accumulation of aluminum oxide. (c) $\mathrm{Na}^{+}$is a native component in PEDOT:PSS, and is thus used as a marker for PEDOT:PSS. (d) $\mathrm{Al}^{2+}$ defines the non-oxide form of the aluminum electrode, which is observed to become oxidated and to dissolve in the silver layer for decreasing cell performance. The schematics on top of the plots illustrate the part of the layer stack the data were extracted from.

partly dissolving in P3HT:PCBM, a phenomenon that was not observed for $\mathrm{MoO}_{3}$ in the IMEC device.

3.4.3 The Risø DTU devices. The layer composition of the Risø DTU P device is Ag-PEDOT:PSS-P3HT:PCBM-ZnO-ITO 


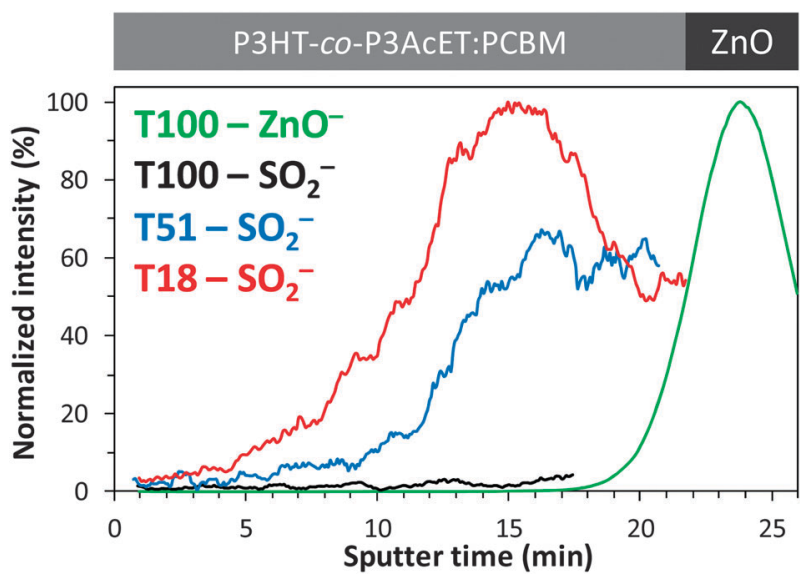

Fig. 18 TOF-SIMS depth profiles for Risø DTU S cells exposed to full sun conditions. $\mathrm{SO}_{2}{ }^{-}$is a mass spectral marker for an unknown $\mathrm{R}-\mathrm{SO}_{x}$ species that is increasing in intensity and evolving at the P3HTco-P3AcET:PCBM/ZnO interface. $\mathrm{ZnO}^{-}$is a mass spectral marker for $\mathrm{ZnO}$ and is included to define the $\mathrm{ZnO}$ layer for clarity. The schematic on top of the plot illustrates the part of the layer stack the data were extracted from.

and the Risø DTU S device differs only by using P3HT-coP3AcET instead of P3HT. Due to the thick plastic encapsulation it was necessary to delaminate the device prior to analysis. The device delaminated at the PEDOT:PSS/P3HT:PCBM interface, which left the device without the upper electrode. It was not possible to analyze the peeled off encapsulationAg-PEDOT:PSS layer stack because of the thickness of the Ag layer $(5 \mu \mathrm{m})$ and the PEDOT:PSS layer $(10 \mu \mathrm{m})$, which is too thick to be analyzed with the sputter properties in question. That leaves the P3HT:PCBM(P3HT-co-P3AcET)-ZnO-ITO layer stack to be analyzed. No trends were observed for any of the mass spectral markers with respect to cell performance for the Risø DTU P device. However, for the Risø DTU S device one trend was observed, which is shown in Fig. 18 for a sputter time window corresponding to the P3HT-co-P3AcET-ZnO layer stack.

The mass spectral marker $\mathrm{SO}_{2}{ }^{-}$for the Risø DTU S device is observed to increase systematically with decreasing cell performance. The shape of the profiles suggests that the phenomenon originates from within the $\mathrm{ZnO}$ layer. The species responsible for the mass spectral marker $\mathrm{SO}_{2}{ }^{-}$must be a $\mathrm{R}-\mathrm{SO}_{x}$ species ( $\mathrm{R}=\mathrm{H}$, organic, or metal). The $\mathrm{ZnO}$ layer contains trace amounts of a variety of inorganic and organic impurities.

However, it makes little sense that migration of that species into the active material should be affected by whether P3HTco-P3AcET or P3HT is used in the active material. A less likely explanation could be oxidation of the thiophene sulphur by something very reactive originating from within the $\mathrm{ZnO}$ layer (e.g. $\mathrm{O}_{2} \mathrm{H}^{-}$), but it makes little sense that $\mathrm{P} 3 \mathrm{HT}$ is not equally affected by it. The Risø DTU S device turned out to be more stable than Risø DTU P, i.e. it took 200 hours longer to degrade. It is difficult to conclude on how much the phenomenon described in Fig. 18. affects the cell performance, or whether it affects it at all.

3.4.4 The Holst and ISE devices. The cell configuration of the Holst cell is Al-LiF-P3HT:PCBM-PEDOT:PSS-SiN,Ag and the ISE cell configuration is Au-PEDOT:PSSP3HT:PCBM-Cr-Al-Cr. The ISE device was unavoidably delaminated leaving the P3HT:PCBM-Cr-Al-Cr part of the layer stack for analysis. The raw depth profiling data were carefully investigated for both devices in order to extract possible trends between mass spectral marker intensities and cell performance. No trends were found in any of the layers and interfaces.

As stated earlier in the text no oxygen incorporation could be detected in the active materials, and no other chemical changes are observed in the devices for decreasing cell performance. No electrode oxidation was observed, no layer thickening was observed, and no interlayer mixing was observed. Apparently it is not possible to detect the cause of degradation, suggesting that the phenomenon or phenomena are not chemical in nature (e.g. delamination at interfaces) or simply too subtle to detect using this analytical technique.

\section{Conclusions}

The work presented in this article is part of a large interlaboratory study that resulted from the 3rd International Summit on Organic Photovoltaic Stability (ISOS-3). The collaboration involved six laboratories that produced seven distinct sets of OPV devices that were degraded under identical conditions in accordance with the ISOS protocols. The degradation experiments lasted 1830 hours and involved more than 300 cells on more than 100 devices. The devices were analyzed and characterized at different points of their lifetime by a large number of non-destructive and destructive techniques in order to describe specific degradation mechanisms responsible for the deterioration of the photovoltaic activity that lead to insufficient lifetimes.

The present work is a systematic study of the ISOS-3 devices using TOF-SIMS in order to identify specific degradation mechanisms responsible for the deterioration of the photovoltaic activity. It was only possible to detect degradation in cells that were exposed to the harshest conditions (AM1.5G, $1000 \mathrm{~W} \mathrm{~m}^{-2}, 85 \pm 5{ }^{\circ} \mathrm{C}$ ). Two devices had impermeable encapsulations and it was not even possible under the harshest conditions to detect any form of chemical degradation as a function of cell performance, which suggests that degradation is not chemical in nature or too subtle to detect using the technique in question.

Photo-oxidation of the active layer (P3HT:PCBM) used in six of the seven devices was quantitatively monitored as a function of cell performance by correlating surface obtained XPS data with bulk obtained TOF-SIMS data. This calibration was complicated by various factors such as being sensitive towards experimental conditions, and the occurrence of a charge transfer complex between molecular oxygen and P3HT. No photo-oxidation could be detected in the two devices with impermeable encapsulations consistent with expectations. Two devices had so-called semi-impermeable encapsulations and both exhibited an apparent linear relationship in oxygen incorporation for decreasing cell performance, which suggests that photooxidation of the active material could be the dominant degradation mechanism. Using P3HT-co-P3AcET instead of P3HT in the devices with semi-permeable encapsulation induces stability, which is believed to be morphological stability causing less 
oxygen to be incorporated resulting in a longer lifetime. Two devices had no encapsulation and exhibited, at first, slow photo-oxidation of the active material that accelerated later in the degradation tests. Photo-oxidation behaviour with respect to the active layer was different for the two types of encapsulation, but the degree of photo-oxidation was surprisingly on the same order of magnitude.

Attempts were made to correlate degradation patterns in LBIC images and TOF-SIMS total ion images for an encapsulated IMEC device with the architecture $\mathrm{Al}-\mathrm{Ag}-\mathrm{MoO}_{3}-$ P3HT:PCBM-ZnO-ITO. It was concluded that localized loss of current in the cells as described by the LBIC images is not related to a chemical phenomenon at the $\mathrm{MoO}_{3} / \mathrm{P} 3 \mathrm{HT}$ :PCBM interface. No correlations could be found in any of the other layers and interfaces, which suggests that the degradation mechanism in question is not detectable by the technique used.

The raw depth profiling data were screened in order to extract possible correlations between the mass spectral data and loss in cell performance that could assist in identifying specific degradation mechanisms and possibly support conclusions drawn in the first three ISOS-3 reports. Several trends were discovered that could be contributing to the overall degradation of the photovoltaic performance.

The trends for the IMEC device were observed to be:

- Increased migration of $\mathrm{Al}_{2} \mathrm{O}_{3}$ from either the $\mathrm{Al} / \mathrm{Ag}$ interface or from the bulk $\mathrm{MoO}_{3}$ layer to the $\mathrm{Ag} / \mathrm{MoO}_{3}$ interface for decreasing cell performance.

- The additional $\mathrm{Al}_{2} \mathrm{O}_{3}$ layer and the $\mathrm{Al}_{2} \mathrm{O}_{3}$ from the $\mathrm{Al}$ interfaces accumulate for increasing illumination time and thus for decreasing cell performance.

- When the IMEC device is encapsulated no $\mathrm{Al}_{2} \mathrm{O}_{3}$ is found at the $\mathrm{Al} / \mathrm{Ag}$ interface, but the additional $\mathrm{Al}_{2} \mathrm{O}_{3}$ layer is still present.

- Trace amounts of $\mathrm{Ag}_{2} \mathrm{O}$ were detected that exhibited a very weak increase for decreasing cell performance.

The trends for the NREL device were found to be:

- Accumulation of $\mathrm{Al}_{2} \mathrm{O}_{3}$ for decreasing cell performance.

- Dissolution of $\mathrm{Al}$ and $\mathrm{Al}_{2} \mathrm{O}_{3}$ in the $\mathrm{Ag}$ electrode for decreasing cell performance possibly catalyzed by water or acid from PEDOT:PSS.

- Thickening of the Ag electrode for decreasing cell performance due to the addition of $\mathrm{Al}_{2} \mathrm{O}_{3}$.

- Partly dissolution of PEDOT:PSS in the active layer (P3HT:PCBM) for decreasing cell performance.

One trend was found for the Risø DTU S device:

- The concentration of an unknown $\mathrm{R}-\mathrm{SO}_{x}$ species migrating out from within the $\mathrm{ZnO}$ layer increases for decreasing cell performance, but it is uncertain whether it contributes to the overall degradation.

The present study and the previous studies in this interlaboratory collaboration clearly demonstrate the strength of combining complementary analysis techniques on systematically prepared $\mathrm{OPV}$ devices in order to gain improved knowledge of the dominant degradation mechanisms responsible for loss of photovoltaic response. The extensive investigation on OPV stability presented in the series of ISOS-3 reports has significantly improved the understanding of degradation behaviour in OPV devices, which is a vital step towards large scale application of organic solar cells.

\section{Acknowledgements}

This work has been supported by the Danish Strategic Research Council (2104-07-0022), EUDP (j.no. 64009-0050, 64009-0051) and the Danish National Research Foundation. Partial financial support was also received from the European Commission as part of the Framework 7 ICT 2009 collaborative project HIFLEX (grant no. 248678), partial financial support from the EUIndian framework of the "Largecells" project that received funding from the European Commission's Seventh Framework Programme (FP7/2007-2013. grant no. 261936), partial financial support was also received from the European Commission as part of the Framework 7 ICT 2009 collaborative project ROTROT (grant no. 288565) and from PVERA-NET (project acronym POLYSTAR). are due to CONACYT (México) for the PhD scholarship awarded to G. T.-E; to the Spanish Ministry of Science and Innovation, MICINN-FEDER project ENE2008-04373; to the Consolider NANOSELECT project CSD2007-00041; to the Xarxa de Referència en Materials Avançats per a l'Energia, XaRMAE of the Catalonia Government (Spain). RR and HH are grateful for financial support from the Thuringian Ministry of Culture and the German Federal Ministry of Education and Research in the frameworks of FIPV II and PPP (contract number 13N9843), respectively. DMT acknowledges generous support from the Inger and Jens Bruun Foundation through The American-Scandinavian Foundation.

\section{References}

1 Polymeric Solar Cells: Materials, Design, Manufacture, ed. F. C. Krebs, DEStech Publications, 2010.

2 Polymer Photovoltaics: A Practical Approach, ed. F. C. Krebs, SPIE Press Monograph, 2008.

3 T. D. Nielsen, C. Cruickshank, S. Foged, J. Thorsen and F. C. Krebs, Sol. Energy Mater. Sol. Cells, 2010, 94, 1553-1571.

4 M. A. Green, K. Emery, Y. Hishikawa, W. Warta and E. D. Dunlop, Prog. Photovoltaics, 2011, 19, 565-572.

5 R. F. Service, Science, 2011, 332, 293.

6 F. C. Krebs, J. Fyenbo, D. M. Tanenbaum, S. A. Gevorgyan, R. Andriessen, B. Remoortere, Y. Galagand and M. Jørgensen, Energy Environ. Sci., 2011, 4, 4116-4123.

7 M. Jørgensen, K. Norrman and F. C. Krebs, Sol. Energy Mater. Sol. Cells, 2008, 92, 686-714.

8 M. Jørgensen, K. Norrman, S. A. Gevorgyan, T. Tromholt, B. Andreasen and F. C. Krebs, Adv. Mater., 2012, 24, 580-612.

9 Stability and Degradation of Organic and Polymer Solar Cells, ed. F. C. Krebs, Wiley, 2012.

10 A. Seemann, T. Sauermann, C. Lungenschmied, O. Armbruster, S. Bauer, H. J. Egelhaaf and J. Hauch, Sol. Energy, 2011, 85, $1238-1249$.

11 M. T. Lloyd, C. H. Peters, A. Garcia, I. V. Kauvar, J. J. Berry, M. O. Reese, M. D. McGehee, D. S. Ginley and D. C. Olson, Sol. Energy Mater. Sol. Cells, 2011, 95, 1382-1388.

12 D. M. Tanenbaum, H. F. Dam, R. Rösch, M. Jørgensen, H. Hoppe and F. C. Krebs, Sol. Energy Mater. Sol. Cells, 2012, 97, 157-170.

13 M. Seeland, R. Rösch and H. Hoppe, J. Appl. Phys., 2011, 109, 064513 .

14 M. O. Reese, S. A. Gevorgyan, M. Jørgensen, E. Bundgaard, S. R. Kurtz, D. S. Ginley, D. C. Olson, M. T. Lloyd, P. Morvillo, E. A. Katz, A. Elschner, O. Haillant, T. R. Currier, V. Shrotriya, M. Hermenau, M. Riede, K. Kirov, G. Trimmel, T. Rath, O. Inganäs, F. Zhang, M. Andersson, K. Tvingstedt, M. LiraCantu, D. Laird, C. McGuiness, S. Gowrisanker, M. Pannone, M. Xiao, J. Hauch, R. Steim, D. F. M. DeLongchamp, R. Rösch, H. Hoppe, N. Espinosa, A. Urbina, G. Yaman-Uzunoglu, 
J.-B. Bonekamp, A. J. J. M. van Breemen, C. Girotto, E. Voroshazi and F. C. Krebs, Sol. Energy Mater. Sol. Cells, $2011,95,1253-1267$.

15 D. M. Tanenbaum, M. Hermenau, E. Voroshazi, M. T. Lloyd, Y. Galagan, B. Zimmermann, M. Hösel, H. F. Dam, M. Jørgensen, S. A. Gevorgyan, S. Kudret, W. Maes, L. Lutsen, D. Vanderzande, U. Würfel, R. Andriessen, R. Rösch, H. Hoppe, G. Teran-Escobar, M. Lira-Cantu, A. Rivaton, G. Y. Uzunoğlu, D. Germack, B. Andreasen, M. V. Madsen, K. Norrman and F. C. Krebs, $R S C A d v$., 2012, 2, 882-893.

16 R. Rösch, D. M. Tanenbaum, M. Jørgensen, M. Seeland, M. Bärenklau, M. Hermenau, E. Voroshazi, M. T. Lloyd, Y. Galagan, B. Zimmermann, U. Würfel, M. Hösel, H. F. Dam, S. A. Gevorgyan, S. Kudret, W. Maes, L. Lutsen, D. Vanderzande, R. Andriessen, G. Teran-Escobar, M. Lira-Cantu, A. Rivaton, G. Y. Uzunoğlu, D. Germack, B. Andreasen, M. V. Madsen, K. Norrman, H. Hoppe and F. C. Krebs, Energy Environ. Sci., 2012, 5, 6521-6540.

17 G. Teran-Escobar, D. Tanenbaum, E. Voroshazid, M. Hermenau, K. Norrman, M. T. Lloyd, Y. Galagan, B. Zimmermann, M. Hösel, H. F. Dam, M. Jørgensen, S. A. Gevorgyan, S. Kudret, W. Maes, L. Lutsen, D. Vanderzande, U. Würfel, R. Andriessen, R. Rösch, H. Hoppe, A. Rivaton, G. Y. Uzunoğlu, D. S. Germack, B. Andreasen, M. V. Madsen, E. Bundgaard, F. C. Krebs and M. Lira-Cantu, Phys. Chem. Chem. Phys., 2012, DOI: 10.1039/C2CP40821J.
18 M. Hermenau, M. Riede, K. Leo, S. A. Gevorgyan, F. C. Krebs and K. Norrman, Sol. Energy Mater. Sol. Cells, 2011, 95, 1268-1277.

19 M. S. A. Abdou, F. P. Orfino, Y. Son and S. Holdcroft, J. Am. Chem. Soc., 1997, 119, 4518-4524.

20 A. Guerrero, P. P. Boix, L. F. Marchesi, T. Ripolles-Sanchis, E. C. Pereira and G. Garcia-Belmonte, Sol. Energy Mater. Sol. Cells, 2012, 100, 185-191.

21 A. Aguirre, S. C. J. Meskers, R. A. J. Janssen and H.-J. Egelhaaf, Org. Electron., 2011, 12, 1657-1662.

22 B. A. Mattis, P. C. Chang and V. Subramanian, Synth. Met., 2006, 156, 1241-1248.

23 E. Voroshazi, B. Verreet, A. Buri, R. Müller, D. Di Nuzzo and P. Heremans, Org. Electron., 2011, 12, 736-744.

24 K. Norrman, N. B. Larsen and F. Krebs, Sol. Energy Mater. Sol. Cells, 2006, 90, 2793-2814.

25 K. Norrman, S. A. Gevorgyan and F. C. Krebs, ACS Appl. Mater. Interfaces, 2009, 1, 102-112.

26 F. C. Krebs and K. Norrman, Prog. Photovoltaics, 2007, 15, 697-712.

27 K. Norrman and F. Krebs, Sol. Energy Mater. Sol. Cells, 2006, 90, 213-227.

28 M. Lira-Cantu, K. Norrman, J. W. Andreasen and F. C. Krebs, Chem. Mater., 2006, 18, 5684-5690.

29 K. Norrman, M. V. Madsen, S. A. Gevorgyan and F. C. Krebs, J. Am. Chem. Soc., 2010, 132, 16883-16892.

30 M. V. Madsen, K. Norrman and F. C. Krebs, J. Photonics Energy, $2011,1,011104$ 